Sheffield Hallam

University
Centre for

Regional Economic and Social Research

\title{
Cross-sector review of affordability support: an evidence review for the Consumer Council for Water
}

March 2021 


\section{Cross-sector review of affordability support: an evidence review for the Consumer Council for Water}

Author(s):

Professor Aimee Ambrose

Jan Gilbertson

Beth Speake

Dr Emma Bimpson

Dr Lindsey McCarthy

Dr Sam Ramsden

March 2021

DOI: $10.7190 /$ cresr.2021.6894611266 


\section{Acknowledgements}

The research team would like to thank the Consumer Council for Water for appointing us to this contract and particularly Andrew White (Senior Policy Manager) and Liz Cotton (Research Manager) for their support and guidance which proved invaluable in completing this review within tight timescales. We would also like to thank all those who gave up their time to participate in interviews and the stakeholder workshop-your insights and feedback have been key in shaping this report and ensuring it is optimally useful to the water sector. 


\section{Contents}

Foreword

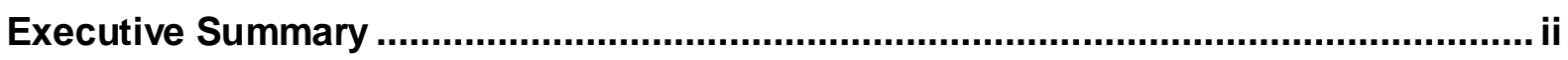

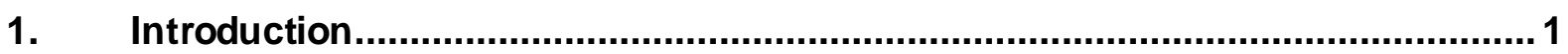

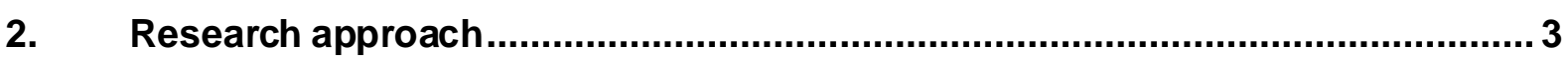

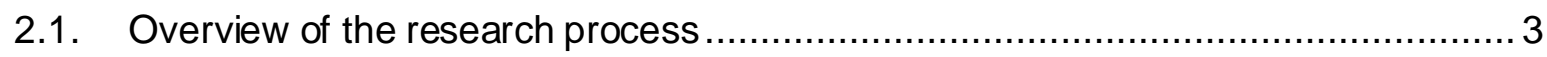

2.2. Description of the research process ............................................................

3. Current practice: affordability support measures and initiatives in essential

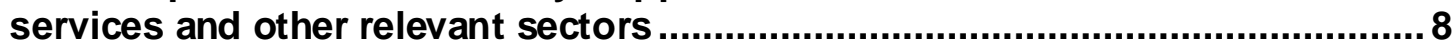

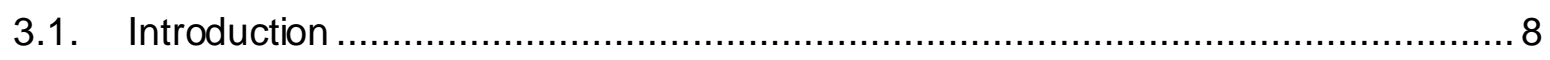

3.2. What affordability support is offered in the water sector? ................................. 8

3.3. What is being offered in terms of affordability support in other sectors? .............. 10

4. Cross sector good practice in the development, delivery and promotion of affordability support to vulnerable customers.................................................... 15

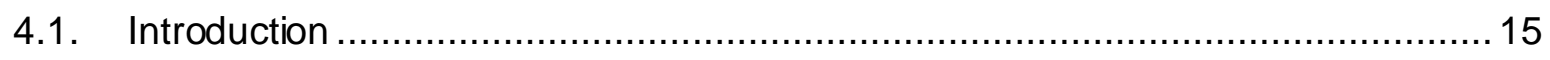

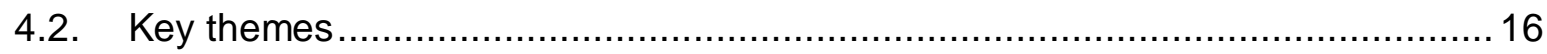

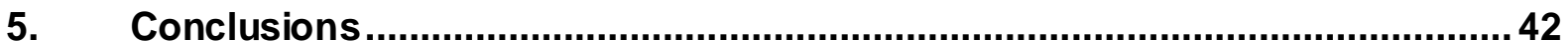

5.1. Overview of key points and recommendations.............................................. 42

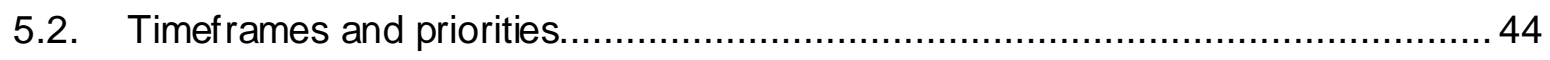

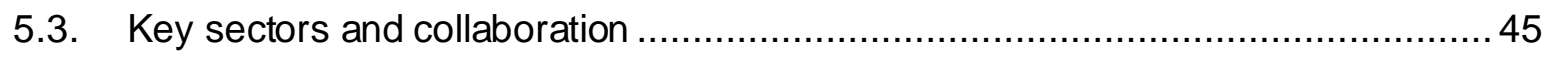

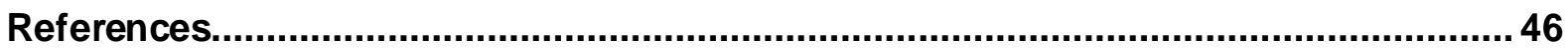




\section{Foreword}

Over the last decade there has been a significant increase in the range and scope of financial assistance measures provided by water companies in England and Wales to support customers who would otherwise struggle to pay their household water and sewerage bills. However, not all households are receiving the support they need, and the economic impacts of the COVID19 pandemic are likely to drive greater need for support.

The economic consequences of the coronavirus pandemic have raised both immediate and longer-term challenges for the water Industry in terms of its support for financially vulnerable households. The measures put in place by the sector, combined with the broader Government support mechanisms, have so far proved effective in

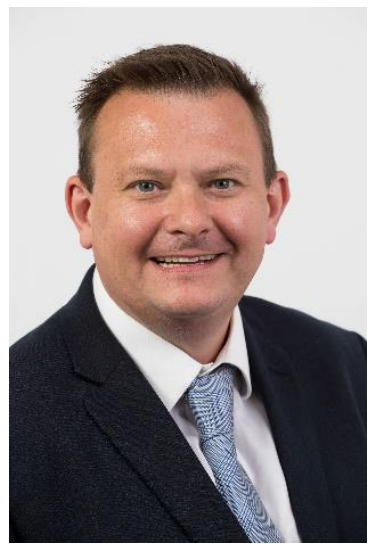
ensuring many customers facing potential financial vulnerability have been able to stay afloat, and have not fallen behind with water charges. However, the longer-term impact on household financial circumstances remains of considerable concern. In particular, rises in unemployment levels make water charges and other bills less affordable for many households. It is vital that the sector's future approach to supporting households is capable of meeting these challenges.

In October 2020, the UK and Welsh Governments asked CCW to undertake an independent review of the current affordability support for financially vulnerable water customers, and to identify if changes to existing measures, and delivery mechanisms could provide greater benefits to consumers facing financial pressures.

In undertaking the review we have sought to gather insights and evidence from a range of sources. We were particularly keen to ensure that, in reaching our conclusions and recommendations, we took account of examples of good practice from other sectors which might be transferable to water. We were also keen to ensure we had good visibility of any opportunities which exist for cross sector collaboration.

We were very pleased to be able to commission Sheffield Hallam University's Centre for Regional Economic and Social Research to undertake this cross-sector analysis of affordability assistance measures to inform the review, and our wider work on behalf of consumers. Their previous analysis, undertaken for us in 2016 , has been very valuable in helping inform our work and the progress of the sector since that time. I know this new piece of work will enable us to achieve further strides towards ensuring that highly effective financial support is available and reaches all those who need it.

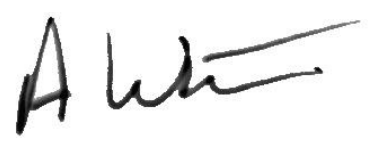

\section{Andrew White, Senior Policy Manager}

The Consumer Council for Water 


\section{Executive Summary}

\section{Introduction}

In November 2020, the Centre for Regional Economic and Social Research (CRESR) were commissioned by the Consumer Council for Water (CCW) to conduct an evidence review of approaches to affordability support (including their nature, delivery mechanisms and approaches to engaging vulnerable and hard to reach customers) across a range of essential services. The purpose of this project is to help inform a broader review of affordability assistance underway across the water sector in England and Wales by identifying good practice lessons in relation to affordability support from other key sectors and assessing their transferability to the water sector. As part of the commission, particular emphasis was placed on identifying good practice and lessons relevant to the engagement of vulnerable and hard to reach households in affordability support with the aim of avoiding or alleviating water poverty.

The project has been guided by five key research questions, set by the client:

1. What relevant affordability support/utility poverty measures and initiatives are being deployed in relevant sectors?

2. How does affordability support provided by other sectors compare to that provided by the water sector in terms of: mechanisms; communication; inclusivity; reaching the hard to reach?

3. What examples of good practice and lessons can be identified in relation to the delivery and promotion of support to financially vulnerable customers from utilities, industries and organisations?

4. How transferable is this good practice to the water sector particularly in the context of Covid-19?

5. What opportunities exist for cross sector collaboration with the aim of improving practice in relation to affordability support?

\section{Methods}

This report has been informed by three key research activities: the systematic review of $\sim 180$ publications spanning more than 10 sectors or service areas; in-depth interviews with 10 senior stakeholders representing six different sectors and detailed notes taken at a workshop with 15 water company representatives. This combination of activities allowed us to take account of published sources detailing practice and good practice in relation to the design and targeting of affordability support and related initiatives whilst also garnering insights into unpublished knowledge of approaches to affordability support and the engagement of harder to reach customers held within relevant organisations. The workshop with water sector representatives and water companies provided us with an opportunity to test the good practice identified in terms of transferability to the water sector. Moreover, the workshop afforded us greater insights into practice and innovation within the water sector, helping us to understand how the sector compares to good practice standards within other essential services sectors. 
This mix of research activities proved effective in generating awealth of reliable and up to date material from which to distil a series of key good practice themes which in turn formed the basis for a series of recommendations for the water sector.

\section{Key findings and recommendations}

The report begins with a review of current practice in relation to affordability support initiatives and associated delivery mechanisms across key sectors including energy, housing, health and advice. In this section we were only able to touch on a selection of the diversity of support measures and initiatives offered across these essential services. The key conclusion being that current practice is highly diverse both within and between sectors in terms of the nature of the support offered, eligibility criteria applied, delivery mechanisms, geographical coverage, funding models and customers targeted. This raises challenges for the exchange of good practice within and between sectors and services and presents a challenge to vulnerable customers trying to navigate this complex support landscape. In this vein, two key points emerged that were reinforced at several points in the report:

- First, that a greater level of consistency and coordination within the water sector between water companies and inter-sector between essential service providers more broadly is highly desirable in terms of better meeting the needs of vulnerable customers and supporting progress and innovation in relation to affordability support.

- Second, an individual requiring affordability support in relation to one essential service is highly likely to require support across them all, although they may have their own ideas about which service takes priority.

\section{Shared platforms, data sharing and a streamlined customer journey}

The identification of these two key points led to consideration of the emerging case for digital mechanisms to enable essential service providers to offer coordinated support to vulnerable customers and to streamline customer support journeys. The discussion around this possibility is set out in section 4.2.2 Shared platforms, data sharing and a streamlined customer journey. This section concluded by recognising that there were many stubborn obstacles to the realisation of a cross-sector platform of this nature but that it remains a long-term aspiration. The interim recommendation for the water sector was therefore to help lay the foundations for this possibility by continuing to participate in various initiatives seeking to improve data sharing and matching between essential service providers; for water companies to continue to lead or participate in more localised pilots of such platforms and to capture and share the resultant learning. It was also argued that there is considerable incentive for the water sector to push ahead with efforts to streamline the customer journey, given that water arrears are the second largest form of debt owed to government and utilities (NAO, 2018).

This section also added to the case for improving consistency of eligibility criteria and the affordability assistance offer between water companies in preparation for closer integration. Energy UK's Vulnerability Commitment is held up as best practice throughout and a commitment of this nature within the water sector would represent akey step towards a greater degree of consistency across the sector in terms of the quality and availability of support, eligibility criteria and identifying those in need.

\section{Affordability support programme design and co-production}

In section 4.2.1 Affordability support programme design and co-production, discussion turned to the makeup of affordability programme designers, co-production and the ways in which it can support the creation of a vulnerability focussed environment. Based on the material presented in this section, the water sector is urged (as a long-term goal) to take every opportunity to diversify the characteristics of policy developers and programme designers to reduce unconscious bias in service design. In the more immediate term, we suggest working towards a sector wide vulnerability commitment that builds on the model put forward by Energy 
UK and encompasses a commitment to co-production and subscription to the BS 18477 standard (Inclusive service provision). In this vein, companies are encouraged to increase (in the immediate term) the level of co-production activity with vulnerable customers, organisations representing their interests and frontline workers across the sector.

\section{Partnership working and trusted intermediaries}

Greater emphasis on co-production necessitates forging closer links with voluntary community sector (VCS) organisations relevant to target groups and co-production specialists (also often found within the VCS), a key recommendation of section 4.2.3 Partnership working and trusted intermediaries. This section demonstrated that partnership working on various levels is established practice within the water sector, that productive relationships have been built between the water and energy sectors and that water companies make extensive use of trusted third parties (usually independent advice organisations) in promoting and delivering affordability support. However, a handful of recommendations were made to help water companies maximise the benefit of partnership working including finding ways to work more closely with third parties to avoid simply passing customers in need of affordability support on to a third party provider, with the aim of reducing the distance between water companies and vulnerable customers that results from this; working with a range of partners that represent the breadth of target groups to avoid skewing support towards particular types of customer and using a multi-partner advisory board to review progress and challenge the sector to go further as part of a sector wide vulnerability commitment.

\section{Person-centred approaches to affordability support}

Building on discussions about co-production and working through trusted intermediaries, section 4.2.6 Person-centred approaches to affordability support addresses the rationale for a person-centred approach to affordability support. It explores the role that independent research and the creation of personas and typologies can play in everything from raising board level awareness to improving the design of initiatives, communications and the customer journey. It also discusses the evidence around the power of social relations and emotions in shaping our consumption, our approach to seeking help and the importance of creating an environment where customers feel comfortable sharing their stories. Recommendations include:

- Be responsive to but also see beyond conditions and disabilities and make no assumptions about vulnerable customers.

- Develop highly customised interventions, where necessary, to meet the needs of complex sub-sets of the customer base and approach simple proxies (such as receipt of welfare benefits) and data led approaches to determining eligibility with caution.

- Invest in independent research into the customer base and their experiences as the basis for persona development.

- Monitor outcomes and impacts for customers in receipt of affordability support in the medium and longer term and feed into persona development.

- Re-introduce face to face engagement whenthis proves possible as part of a commitment to making it as easy as possible for customers to be heard.

\section{Diversification of communication channels}

In relation to these latter points, section 4.2.7 Diversification of communication channels makes a clear case for offering customers a broad range of both digital and more traditional ways to communicate and engage with affordability support. The evidence presented highlights how the trend towards offering affordability support only by phone and online is a significant disadvantage to the most vulnerable. The sector is also reminded to ensure that service design does not favour 'active consumers' and develop clear criteria for deciding who 
receives home visits when they return; to match communication innovations to the segments of the customer base most likely to use and benefit from them and keep a record of customers' engagement preferences.

\section{Timeframes and priorities}

The recommendations put forward in this report vary in terms of the timescales over which it is possible to put them into practice and variation in practice across the sector means that some companies will already be delivering on them while others have further to go. The scale of action also varies in the sense that some recommendations can be taken forward at the level of the individual company whilst others require cross-sector commitment and thus may take longer to achieve.

Several recommendations stand out as immediate priorities:

- Beginning work, perhaps under the mentorship of Energy UK and the Commission for Consumers in Vulnerable Circumstances (CCVC), to develop a voluntary vulnerability commitment for the water sector which builds on the energy sector commitment by incorporating an emphasis on co-production and references the BS18477 standard.

- Work closely with co-production specialists and specific VCS organisations to ramp up co-production activity, starting with specific groups that prove consistently hard to engage.

- Make more use of independent research providers to provide a deeper understanding of the customer base, help develop personas and typologies that can raise awareness of the diversity of needs and circumstances that exist within the customer base and inform all aspects of service delivery and design. Linked to this, put in place robust monitoring procedures to track outcomes for those in receipt of affordability support.

- Maintain more traditional communication channels alongside digital options and carefully match communication channels to customer segments.

\section{Key sectors and collaboration}

We also undertook analysis to identify which sectors or service providers have formed the key influences on the recommendations set out in this report. This information has been used to suggest sectors and specific organisations where the water sector might most usefully focus efforts to forge new collaborations. Some suggestions relate to the development of close partnerships focussed on the exchange of good practice and knowledge (i.e. working closely with Energy UK/ the CCVC on a vulnerability commitment or with Citizens Advice on the development of shared platforms) and others to lighter touch 'following' of research and innovations to emerge from particular sectors (i.e. following research emerging from the Fuel Poverty Research Network, the Joseph Rowntree Foundation or the International Energy Agency's collaboration on Hard to Reach energy users). 


\section{Introduction}

In November 2020, the Centre for Regional Economic and Social Research (CRESR) were commissioned by the Consumer Council for Water (CCW) to conduct an evidence review of approaches to affordability support (including their nature, delivery mechanisms and approaches to engaging vulnerable and hard to reach customers) across a range of essential service sectors. The purpose of this project is to help inform a broader review of affordability assistance underway across the water sector (in England and Wales) by identifying good practice from other key sectors and assessing the extent to which they may be transferable to the water sector in order to improve policy and practice in relation to affordability support. As part of the commission, particular emphasis was placed on identifying good practice and lessons relevant to the engagement of vulnerable and hard to reach households in affordability support aimed at avoiding or alleviating water poverty.

For the purposes of this report, we have taken a broad and flexible approach to defining vulnerable and hard to reach groups, which takes account of the following key points from the relevant literature:

- Vulnerability can be due to circumstances (e.g., caused by ill health, bereavement, unemployment, location, access to technology) and/or characteristics (e.g., age, gender, ethnicity, language), is not necessarily directly linked to income and can be temporary or longer term (Ofgem, 2019).

- Hard to reach is a context specific concept and cannot be described by a single list of groups likely to miss out on services (Ashby et al., 2020 a, 2020b).

- Conceptualisations of hard-to-reach groups should problematise service providers for not making their services inclusive, not the characteristics of senice users (lbid).

- One way of looking at it is that hard to reach individuals and households are those who have not yet participated despite ongoing outreach efforts (Ibid).

- Hard to reach households are those not seen or heard in a service context and are unlikely to self-identify as such (Flanagan and Hancock, 2010).

- Vulnerability can make you hard to reach and being hard to reach can make you vulnerable but the two are not always synonymous (Ambrose et al., 2019) .

This review focusses on forms of affordability support intended to avoid or alleviate an inability to afford to access an essential service to an adequate level. It may include things like social tariffs, price caps, payment plans and grants. Many essential service providers offer affordability support to their customers but the forms it takes varies greatly within and between sectors and services and the mechanisms through which it is delivered are also hugely diverse. 
The literature review, which represented the starting point for this research, identified good practice and lessons in the provision of affordability support from across (inter alia) the energy, advice, housing, health and voluntary community (VCS) sectors and assessed the extent to which the water sector could learn from these other sectors. Interviews with senior stakeholders working across a variety of essential services, including water, and a workshop with water sector representatives allowed us to access unpublished insights and also to assess the extent to which practice in the water sector aligns with good practice identified in other sectors. More details on the methodology underpinning the research can be found in chapter 2 , below.

The project has been guided by five key research questions set by the client. These are listed below alongside details of where each question is primarily addressed:

1. What relevant affordability support/utility poverty measures and initiatives are being deployed in relevant sectors? (Chapters $3 \& 4$ )

2. How does affordability supportprovided by other sectors compare to that provided by the water sector in terms of: mechanisms; communication; inclusivity and reaching the hard to reach? (Chapters 3\&4)

3. What examples of good practice and lessons can be identified in relation to the delivery and promotion of supportto financially vulnerable customers from utilities, industries and organisations? (Chapter 4)

4. How transferable is this good practice to the water sector, particularly in the context of Covid-19? (Chapters 3\&4)

5. What opportunities exist for cross sector collaboration? (Chapter 5: Conclusions)

This report comprises of four chapters in addition to this one:

- $\quad$ Chapter 2 outlines the methodology underpinning the study.

- Chapter 3 provides an account of current practice in relation to affordability support measures and initiatives in essential services and other relevant sectors.

- Chapter 4 synthesises the findings from across the different strands of the project and identifies good practice and lessons identified from other relevant sectors, which is of relevance to the water sector.

- Chapter 5 summarises the recommendations made on the basis of the research and sets out concluding thoughts including suggestions for cross sector collaboration between the water and other sectors. 


\section{Research approach}

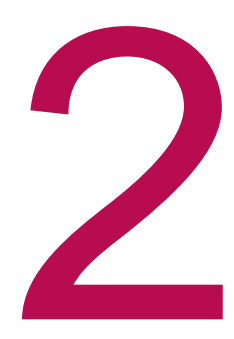

\subsection{Overview of the research process}

The methodology for the review comprised of five sequential strands, as summarised by the diagram below and outlined in more detailed in section 2.2.

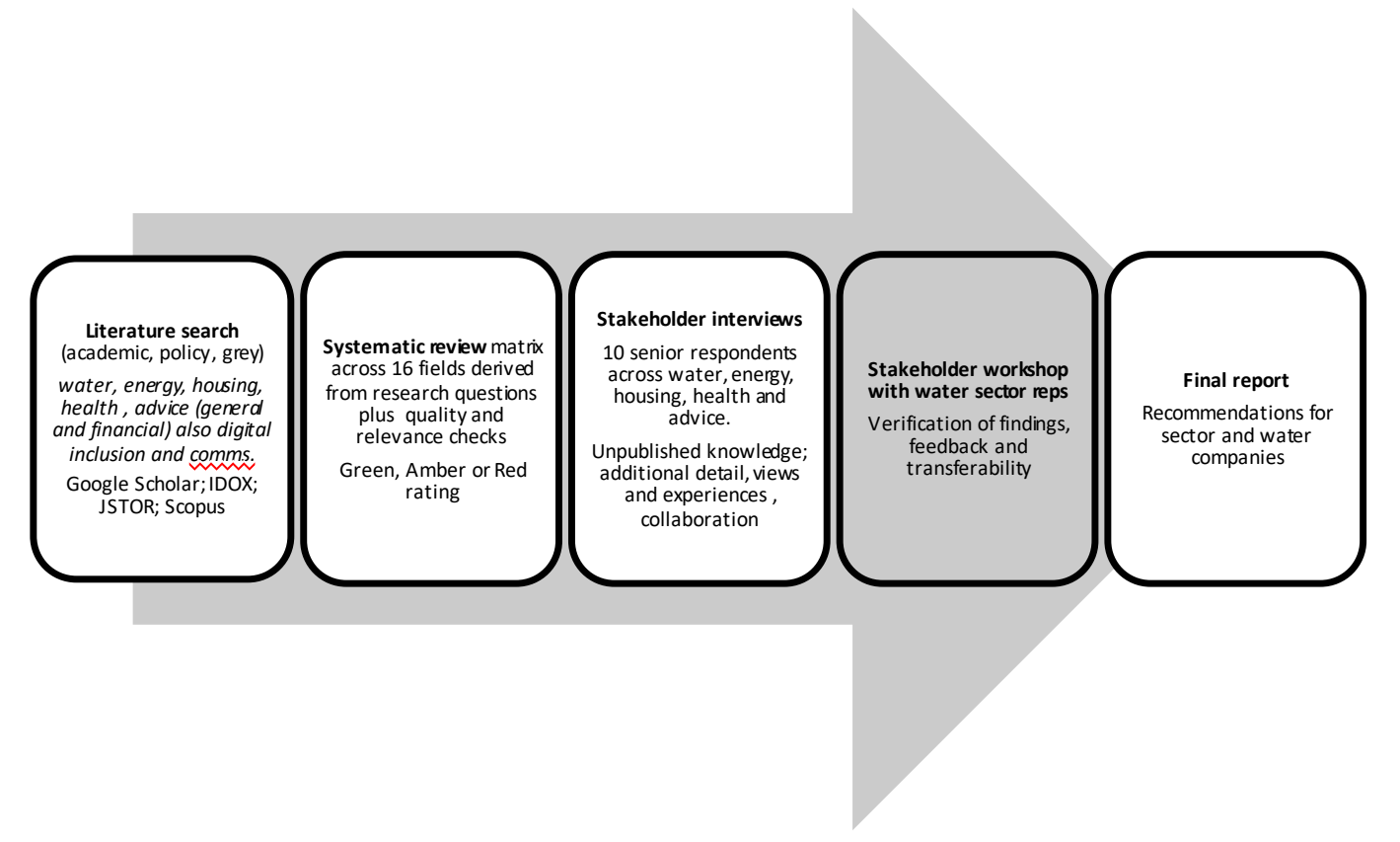

\subsection{Description of the research process}

\subsubsection{Systematic evidence review}

The research process began with an evidence review of theory and practice in relation to the targeting, delivery, promotion and communication of affordability assistance and other relevant support initiatives across a range of sectors providing essential services (including but not limited to water; energy; health; housing and advice) as well as other practice relevant to the effective engagement of hard-to-reach customers, including that emerging in response to Covid-19. This initial stage was based on the established principles of systematic reviewing - a rigorous approach to evidence reviewing with the capacity to identify, appraise (in terms of quality, reliability and relevance) and synthesise all evidence related to a particular set of research objectives. Systematic reviews aim to identify all sources relevant to core research questions and to identify what can reliably be said on the basis of these sources. Systematic reviewing is accountable, replicable and ensures that all sources are assessed against the same criteria and that the review stays focussed on the research objectives. 
It begins with the detailed development of a search strategy for the identification of a comprehensive set of sources for review and the creation of a detailed review matrix to guide the systematic review of all sources identified.

\subsubsection{Strand 1: The search strategy}

To identify all sources of relevance to the research objectives, a four-prong search strategy was employed spanning academic, policy and grey literature. This approach included drawing on the research team's awareness of relevant sources as well as that of the client and various national and international expert communities to which the research team are linked in addition to the use of professional evidence searching services.

The search adopted flexible temporal boundaries looking to identify relevant sources published since around 2010 to ensure inclusion of any relevant material missed in the last review (2016) and to ensure that where older sources represent the extent of existing knowledge and thinking in a particular sector, that is established. The search also took account of both the national and international literature, with international sources carefully assessed for their relevance and applicability to the context of England and Wales.

The four prongs of our search strategy were as follows:

- 'In house' knowledge: An initial set of sources were identified using the existing knowledge of the research team and their immediate networks.

- Key terms search: The team concurrently worked with the client to generate a long list of key search terms $(n=58)$ which were used to search the academic, policy and grey literature using Google Scholar and key online libraries and databases, such as JSTOR, SCOPUS and IDOX. Boolean operators were varied to ensure no sources were missed due to this.

- Snowballing: The reference lists attached to each of the relevant sources identified were examined to identify any further sources of relevance.

- Using expert networks: Calls requesting evidence and relevant sources were issued by the team by email through established academic and practitioner networks including JISCMAIL lists such as the Fuel Poverty Research Network list and those relating to welfare reform; vulnerable groups; public health promotion; advice providers and online communities such as Research Users in Social Housing (RUSH). Making use of expert networks is particularly important in the era of Covid-19 where thinking on how to reach and engage households in initiatives with the potential to improve their circumstances is rapidly evolving and where published literature may lag behind current thinking.

The search strategy yielded $\sim 180$ sources for review with the largest number of sources relating to the energy, advice and health sectors. Once we felt satisfied that the number and range of sources identified was sufficient to address the research questions, all relevant material identified (including reports, articles, book chapters, leaflets, blogs, think-pieces etc.) were assembled in one place for systematic review. All sources identified were logged in the review matrix and given an initial categorisation according to the sector they related to. They were then divided between members of the project team for systematic review. Where possible, each member of the review team maintained a focus on material relating to a particular sector or sectors, allowing them to build up detailed knowledge of practice in that sector, aiding the analytical process. 


\subsubsection{Strand 2: Systematic review}

All sources identified through the evidence search were subjected to rigorous systematic review in order to extract insights directly relevant to the research questions, identify good practice and lessons and to pinpoint exact passages, quotes, and fig ures of relevance and assess their reliability and validity. Systematic reviewing will filter out unreliable sources or parts of sources that do not meet key quality control criteria around timeliness; relevance to the research objectives; origins, methodo logical rigour etc.

A review matrix was developed in Excel for the specific purpose of this review. It contained 16 fields which guided the reviewers through the stages of the review, ensuring that each source was thoroughly assessed and treated consistently. The framework asked the reviewer (inter alia) to:

- $\quad$ Provide a short summary of the source.

- Identify and cite specific elements of the source of relevance to each research question.

- Identify which groups the source relates to (i.e., the characteristics that might make them vulnerable or hard to reach in the context of affordability support).

- Work through a series of questions that determine the credibility of the source in terms of timeliness, level of methodological rigour, type and place of publication, motivation for its production, funder, author etc.

- Consider the geography to which the source relates and the extent to which the insights are contextually specific or relevant across different contexts.

- Consider the scale to which the source relates, i.e., does it relate to a locally or regionally specific or a national or international regulation, policy or initiative.

- Detail any examples of good practice or lessons identified by the source.

- Identify any other potentially relevant sources cited within the source.

This process culminated in each source being given a Green, Amber or Red rating, where red is not relevant or sufficiently reliable and green is highly relevant and reliable. Green and Amber sources then formed the basis of the onward analysis.

Of the 180 sources reviewed, 36 were categorised as Green sources (directly relevant and reliable) and 49 as Amber (relevant and credible). Of these, 49 related to the energy sector, 21 to the advice sector including consumer rights; a further 11 sources emanated from the health sector, including medical research; 6 sources came from the water sector; a further 4 sources related to all utilities; 3 sources spoke directly to digital inclusion/exclusion, and 4 to engaging hard-to-reach groups and/or those experiencing multiple disadvantage. The remaining sources were located within the areas of housing and the VCS.

Across these green and amber sources, 37 different vulnerable groups were identified, as follows: 

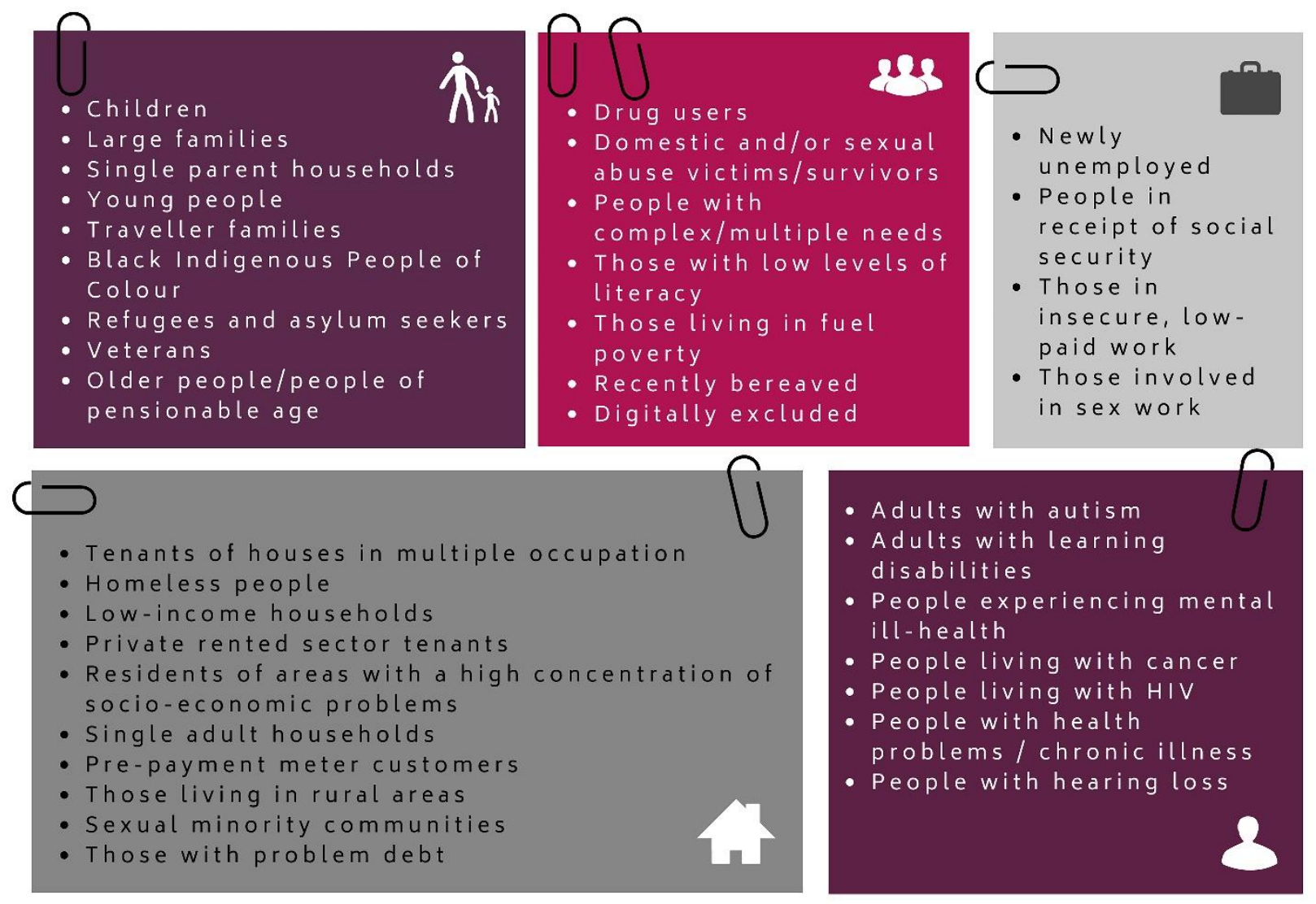

\subsubsection{Strand 3: Light touch analysis and interviews with stakeholders}

Following the completion of the review process, an initial analysis was conducted to identify emerging themes; gaps in existing knowledge and specific initiatives or approaches for further exploration through a programme of stakeholder interviews. To enable this, insights from Green and Amber sources were inputted into qualitative analysis software programme Nvivo and coded according to a framework which allows for both deductive thematic coding (according to the research questions) but also inductive coding, allowing for unanticipated but relevant themes to be identified. This analysis helped to identify who (and which sectors) we should target for the interviews in order to achieve a detailed picture of good practice emerging from arange of sectors.

Following the completion of this light touch analysis, we conducted a series of 10 indepth interviews with stakeholders across a range of sectors to establish detailed and nuanced insights into different approaches to delivering affordability support; engaging hard to reach and vulnerable customers; the impact of Covid-19 on these approaches and to garner detailed examples of good practice.

The most appropriate stakeholders to interview were identified using the findings of the evidence review (i.e., authors of sources that we want to explore in further detail; those responsible for good practice initiatives and mechanisms identified); our own knowledge of individuals and organisations leading innovation in or with vast experience of promoting engagement with affordability initiatives, particularly amongst hard-to-reach groups plus recommendations from the client.

We spoke to representatives of the following organisations or types of organisations:

- CCW. 
- $\quad$ Selected water companies.

- Advice providers: Citizens Advice (energy advice).

- Social housing providers (financial inclusion services).

- Energy consumer advocates (National Energy Action).

- Local authorities (health and fuel poverty interventions).

- Home Improvement Agencies (Foundations Independent Living Trust).

- $\quad$ Trade association for the energy industry (Energy UK).

- Sector regulators (Ofgem, Ofwat).

The interviews were guided by a semi-structured topic guide based around an elaboration of the key research questions and a series of more detailed supplementary questions identified through the light touch analysis, including the detailed exploration of initiatives and practices identified as good practice. The topic guide contained several different sets of questions, each aimed at different types of stakeholders (i.e., those with policy knowledge/ experience of delivery/a frontline focus/ knowledge of specific types of customer).

Following the completion of the stakeholder interviews we used Nvivo software to conduct further analysis of all data (findings from the systematic evidence review plus material from the interviews) to enable us to provide a robust account of key findings and good practice and lessons identified and to formulate a series of draft recommendations to share with the water sector. This exercise enabled the identification of a series of key themes, which were used to structure the presentation of key findings to water sector representatives at a stakeholder workshop (see below) and which (with some modification) provide the structure for Section 4 of this report.

\subsubsection{Strand 4: Online stakeholder workshop with water sector representatives}

In January 2021, an overview of key findings and draft recommendations was shared with representatives of 15 water companies operating in England and Wales plus representatives of CCW. The draft recommendations were then examined in more detail through break-out groups, testing the feasibility of recommendations within the sector, particularly at water company level. The workshop led to the refinement of the recommendations, identified some further sources for review and also generated further insights into good practice and innovation taking place amongst water companies.

\subsubsection{Strand 5: Final analysis and reporting}

Following the online workshop, the final analysis was conducted using Nvivo bringing together all credible data (deemed to be of sufficient quality and relevance) to bear on the five key research questions underpinning the review. A final review of all data coded against each of the five research questions was conducted and the research team agreed a final set of recommendations for inclusion in this report, ensuring that feedback from the online workshop was fully considered. 


\section{Current practice: affordability support measures and initiatives in essential services and other relevant sectors}

\subsection{Introduction}

This chapter covers affordability support measures and initiatives in the water sector and other relevant sectors including energy, housing, health and advice and compares what is being provided in the water sector with support that is offered elsewhere. How affordability support measures and initiatives provided by other sectors compare to that provided by the water sector is considered in terms of the mechanisms and tools used and the way they are delivered.

In this section we can only really touch on a selection of the many support measures and initiatives offered across the water sector and other essential services. It is therefore worth emphasising that affordability support provision across different sectors and within sectors is diverse in terms of the support of fered, eligibility criteria applied, channel provision, coverage and funding models. The clients requiring support also present with varying needs, capabilities and inclination to engage. There are some commonalities in the way that support is delivered in different sectors which are outlined below. However, the lack of consistency of support within and across essential services means that the nature and quality of affordability support delivered can vary widely, and make navigating the support landscape more difficult for those who are struggling.

\subsection{What affordability support is offered in the water sector?}

Water companies provide a range of affordability support options to meet the different needs of their customers. Typically, water companies offer a package of measures which can help customers with short term financial difficulties and provide assistance to customers experiencing longer term affordability problems of arrears and debt.

The main way that water companies support low income customers with affordability is by capping or reducing bills through measures such as social tariffs or schemes like Water Sure. Water companies can use social tariffs to reduce the bills of some of their low-income customers but must consult their own customer base about the level of support provided through such schemes. Water companies offer their own social tariff schemes to low-income customers, but the eligibility criteria applied, the level of support provided and the way tariffs are delivered varies between companies. 
In relation to social tariffs in the water sector, variation between companies is driven by a localised model of customer consent. Under this model, water companies are required to consult with their customer base about the acceptability of social tariffs and the amount they are willing to contribute towards them, leading to considerable variation in the eligibility criteria applied, the level of support provided, and the way tariffs are delivered across companies. However, there are examples of water companies increasing access to social tariffs and increasing support for themamongst their customer base by making contributions directly out of their profits and matching contributions from customers. As mentioned by a senior CCW representative, some work undertaken by CCW suggests that customers are more willing to contribute to social tariffs if they see that their water company is also making a contribution (CCW, 2010).

The WaterSure scheme is a Government mandated scheme (mandated in England) offered by all water companies (including on a voluntary basis by companies in Wales) which limits metered bills for low income high essential water users as measured against the average for that region (although some companies offer an enhanced version with a lower level bill cap). Switching to metered charges can also help some customers save money and to help customers decide if this is the right option for them some companies have introduced a 'Lowest Bill Guarantee' whereby the water company will guarantee that anyone switching to a meter pays no more than they would have done previously, for a certain period of time. If their bill is lower on a meter then the customer pays the lower price. Customers in areas where there is no compulsory metering programme also have the option to switch back to an unmetered bill within two years.

To help customers with managing short term financial stress, water companies offer flexible payment schemes and payment breaks so that customers can spread their payments or defer payments for a period by agreement. Payment breaks were offered by some companies prior to Covid-19 but more recently all companies have used them to help customers through the economic impacts of the pandemic.

For those customers who need help with repaying debt, payment matching schemes will match customer repayments towards a debt usually with an equal payment or in some cases a larger payment by the water company. The Water Direct scheme can also help customers who are in debt as it enables water companies to arrange to take payments direct from a customer's benefits prior to payment. This arrangement can help some customers to manage their budgets but there are limits to the amount companies are permitted to collect direct from benefits.

Other support schemes offered by companies to help those in debt include Charitable Trusts and in-house crisis funds which provide one off grants to clear arrears for household bills including water or other utility bills. Grants can also be used to help buy white goods or other essential household items. Charitable Trusts are operated at arms-length from the water companies that fund them.

Water companies also support customers by helping them increase their income through measures such as benefit entitlement checks to make sure that customers are claiming the full range of benefits they are entitled to. Most companies also have referral arrangements and partnerships with both local and national advice agencies and charities which enable water customers to access specialist financial advice and support.

Finally, water efficiency home visits and audits, usually offered to metered customers, are another way of helping customers identify ways they can save water and therefore reduce their metered bill. 
As this section illustrates, there are lots of innovative examples of affordability support provided by water companies. However, a lack of consistency is a significant issue across the water sector with all companies offering a different mix of affordability support initiatives and operating different eligibility criteria, even in relation to national schemes (i.e. Water Sure). There are also significant variations in the levels of support offered through social tariffs and in the way water poverty is defined. In relation to this latter point, a new programme of work around water poverty is currently being funded by the Northumbrian Water Group with the aim of eradicating water poverty by 2030 . A key initial task is to establish an industry acknowledged definition of water poverty. The water industry trade body Water UK also has a project focussed on that issue.

\subsubsection{How is support delivered?}

Offering affordability support is only part of the picture and the challenge for water companies is getting customers to take up the available support and ensuring that this support reaches customers who need it most.

As outlined by a senior water company representative when interviewed, customers usually approach water companies by ringing or writing in to contact centres. An initial assessment of what the customer needs and whether the problem is a short-term challenge or a longer-term problem is undertaken and the appropriate support put in place. If needed, customers are then referred to third party partnership organisations for further specialist help with things like money management and debt advice.

Partnerships with third party organisations and making sure local and national advice agencies are linked in with water companies' affordability offers is regarded by sector representatives as one of the most effective ways for water companies to deliver affordability support. This is particularly felt to be the case if advice agencies are referring people into social tariff schemes or are able to 'passport' people automatically onto affordability schemes (i.e., because they're in receipt of a qualifying benefit), thus simplifying the process.

An example of the way water companies work with the advice sector is provided by the United Utilities North West Community Advice Hub which is an online 'one stop shop' designed to offer the regional advice community quick and easy access to information and resources which enable them to better support their clients including information on water affordability support. Other companies like Wessex Water have similar online partner hubs and some companies have areas on their website accessible to third party organisations which detail all of the support available.

Many water companies also recognise the value of face-to-face contact as a way of informing customers about affordability support and signing them up to it. Water companies' outreach teams work in their local communities attending community groups and events, conducting door to door visits in order to sign customers up for financial support, and undertaking home water efficiency visits targeted at particular groups of customers e.g., those on meters who are likely to need support.

\subsection{What is being offered in terms of affordability support in other sectors?}

Like the water sector, the energy sector seeks to safeguard customers from unaffordable energy costs by offering price protections or price caps to customers on standard and prepayment tariffs. These price caps are designed to ensure that customers pay a fairer price for their energy, are protected from being over charged and are not charged more than the energy they use actually costs.

A major form of financial support for low-income consumers in the energy sector is the Warm Home Discount (WHD) which has three different elements: the Core Group, 
Broader Group and Industry Initiatives. Energy suppliers with over 250,000 domestic customers are required to participate in the Core Group and Broader Group elements of the scheme. This Government scheme offers a rebate of $£ 140$ to customers and is paid automatically to the 'Core' group of customers who receive the guaranteed element of Pension Credit. Energy suppliers also pay the WHD to a 'Broader' group of customers who have difficulty paying energy bills. For this part of the scheme, energy suppliers have their own qualifying criteria and a limit on the number of customers who can benefit. Customers of participating suppliers must apply directly for support which is generally delivered on a first come, first served basis. The Industry Initiative component of the WHD scheme allows energy suppliers to help fuel poor customers through third parties. Depending on the obligated supplier's programme and third-party provider, it can include advice on energy saving, and help with reducing energy debts.

In the energy sector, customers who are experiencing difficulties paying their bills are generally supported through Industry Initiatives. The money is used to fund specific advice programmes such as the Citizens Advice Energy Advice Programme which is funded by energy suppliers as part of their obligations as the main funders of energy advice provision. Industry Initiatives also enable the energy sector to write off debts and ensure that customers are offered manageable repayment options and plans tailored to their needs. The sector also has protections against disconnections related to debt, but problems with self-disconnection (being unable to afford to top up a pre-payment meter) persist for customers on pre-payment meters. In response to this, Ofgem introduced new protections in December 2020 requiring suppliers to offer certain types of credit e.g., emergency credit built into the meter when customers selfdisconnect and additional credit for vulnerable customers to afford them 'breathing space'.

As with the water industry, energy suppliers fund Charitable Trusts. In addition to providing one off grants to help struggling families, trusts also fund specialist energy debt advisers across energy companies and partner organisations.

Another way that the energy sector supports low-income consumers is through attempting to tackle some of the root causes of fuel poverty. Under the Energy Company Obligation, the Government's energy efficiency scheme, suppliers must promote measures which improve the ability of low income, fuel poor and vulnerable households to heat their homes. This includes actions that result in heating savings, such as the replacement of a broken or inefficient heating system.

In other sectors such as debt advice and housing, affordability support is often delivered through income maximisation, money management and budgeting and debt advice. For example, housing associations often operate projects to assist tenants to maximise their income and enhance their quality of life to reduce the risk of tenancy failure. Online resources including a range of different toolkits and calculators which provide help to improve money management and financial skills are commonly used in the money advice sector and across many other sectors.

For debt and arrears problems with Council Tax payments, utility bills, rent and mortgage arrears there are third party deduction schemes managed by the Department for Work and Pensions (DWP) which allow for money to be taken directly from benefits to pay off debt. The scheme allows payments to be made to certain creditors directly from a benefits payment, helping customers who have issues with budgeting. However, different sectors follow different principles and guidelines for debt management. This can become confusing for customers, making it difficult to understand and manage their debt journey across multiple sectors. 
The voluntary and community sector and other sectors like health frequently use partnerships and outreach projects to deliver affordability support. These initiatives usually train frontline workers from different organisations to act as 'champions' to either inform their clients about the affordability support available, signpost or refer to trusted third parties or to undertake assessments and help people to directly access appropriate support.

One example is the Big Energy Saving Network (BESN) project which is an outreach project, funded by the Department for Business, Energy \& Industrial Strategy (BEIS) and delivered by Citizens Advice. The project helps consumers to take action to reduce their energy bills and improve their energy efficiency and is delivered by a network of over 170 Energy Champions based in organisations and charities across England and Wales. Champions offer advice on energy saving in the home, switching energy suppliers, and guidance on how to access schemes that help vulnerable households stay warm and reduce energy bills. Champions use their local networks and connections to deliver energy advice to existing community groups, and on a oneto-one basis with the consumers they engage via existing services, drop-in events and through local partnerships. The BESN is based on a cascading model with champions further cascading energy advice within the community by training a wide variety of frontline workers to provide energy advice to their consumers.

\subsubsection{Mechanisms and tools}

Affordability support in the energy and water sectors is provided through a combination of Government schemes and funding from companies and customers. Energy suppliers are obligated through regulation to fund and provide support for low-income customers struggling with bills through measures such as the Warm Home Discount and Industry initiatives.

Although there is variation in the way the broader group of the WHD is applied by participating energy suppliers, there is some consistency to the scheme. The WHD provides a set level of rebate for customers and the core element of the scheme is automatically administered using the benefits system through data sharing arrangements with DWP. The WHD is paid to customers as a rebate on their energy bill without an application process.

The energy sector's Industry Initiatives are also a vehicle for funding partner organisations to provide dedicated energy advice programmes which can offer more comprehensive and specialist support to customers, such as Citizen's Advice Energy Advice Programme. This programme provides specialist energy advice services specifically for clients who are in fuel poverty or at risk of being in fuel poverty and is provided alongside general advice. Although partnership arrangements with third party organisations are common in the water sector, providing specific funding for partner organisations to deliver dedicated advice programmes is not. Instead, individual water companies tend to provide funding to support debt advice or using funding for small local projects around a local problem.

If energy companies do not meet their obligations, they are liable to fines which are used to fund fuel poverty projects and support vulnerable consumers through the Energy Redress scheme administered by the Energy Saving Trust on behalf of Ofgem. The scheme distributes voluntary payments made by energy companies that may have breached regulations with the aim of supporting energy consumers in vulnerable situations. Charities in England, Wales and Scotland can apply for funding to deliver projects and services that meet the priorities of the scheme. There is also a small amount of funding available to support projects that develop or trial innovative products or services that will support energy consumers. The scheme has funded a large number of projects ranging from free and impartial energy advice services aimed 
at privately renting households, families or those with cold related health issues, to projects supporting young people living on their own for the first time.

Statutory levies on the financial services industry are also used to fund the Money and Pensions Advice Service (MaPS), an organisation set up by the UK Government. MaPs is an arm's-length body of the DWP providing free money guidance and debt advice services and also funds third party debt advice agencies to deliver support.

\subsubsection{The way they are delivered}

There are some commonalities in terms of the way that affordability support is delivered across different sectors. Many sectors, including the energy and water sectors, work with trusted organisations and typically have partnership and referral arrangements in place with third party advice agencies at a national and local level. These organisations usually provide specialist advice to support affordability work and refer people into affordability schemes or are able to passport people automatically onto schemes. Services are typically delivered via a range of channels including face to face, telephone, online and digitally. For example, MaPS provides free online and telephone money guidance and debt advice services, but also funds a range of third-party debt advice providers who offer a range of debt advice channels through which people can engage. This approach aims to ensure that customers have multiple ways to access debt advice services.

The water industry and other sectors such as housing are adopting the Making Every Contact Count (MECC) approach which originated in the health sector and was highlighted in our last report for the CCW in 2016. This approach encourages staff using routine interactions with customers to deliver brief information about the availability of support. The importance of having the right conversations and training staff to have better understandings of the reasons why people cannot pay and the impact it has on their lives is also recognised across different sectors. There are examples from across the energy and water sectors of companies training staff and creating specialist teams in their contact centres to identify customers in vulnerable circumstances, placing an emphasis on listening to and understanding the customer, while being alert to clues and triggers that suggest a referral to a specialist provider is appropriate.

Training frontline staff and 'champions' to support engagement is a common way of delivering affordability support in different sectors including debt advice, housing and health. This model of delivery enables staff to 'handhold' clients through the process of accessing support and the onward support journey rather than just signposting them to further support. This approach allows support to be tailored to an individual's circumstances and needs, with advisers 'handholding' the client through the whole affordability support journey and integrating a range of support tools, services and other resources to help the client deal with their overall financial situation. Staff in these sectors typically act as a caseworker supporting their client and acting as an intermediary between them and other agencies providing support. The support offered is flexible and holistic, dealing with the client's presenting issue initially but also provides the conditions and relationships of trust necessary to identify and address the cause of the problem.

Across voluntary and statutory services, more collaborative partnerships and approaches to supporting the health and wellbeing of vulnerable people and communities are emerging. These programmes incorporate a wide range of support including financial help and are delivered by cross sector partnerships involving a wide range of professionals. They offer person centred and tailored support which responds to the needs of the person they are dealing with (see Sherriff et al, 2020 as an example). These approaches are discussed in more detail in Section 4.2.6 below. 
Centre for Regional Economic and Social Research | 14 


\section{Cross sector good practice in the development, delivery and promotion of affordability support to vulnerable customers}

\subsection{Introduction}

This chapter sets out the key findings identified through the evidence review (green and amber sources) from across the water, energy, advice, health and housing sectors (policy, academic and grey literature); the interviews with senior stakeholders in addition to insights garnered from the workshop with water sector representatives in January 2021.

Specifically, this chapter focusses on the identification of good practice and relevant ideas and concepts from across these various sources, which are felt to be relevant and potentially transferable to the water sector to help raise awareness of affordability assistance, promote take up and broaden participation across vulnerable and hard to reach groups. Examples of how not to approach affordability assistance or 'lessons' are also included where they are felt to be relevant. The practice identified focusses on different aspects of the provision of affordability assistance. For example, some examples relate to the nature of the assistance on offer and how it is designed; some to the way it is targeted and communicated while other sources highlight mechanisms for delivery. The key findings are organised according to a series of key themes that emerged through inductive analysis of the data.

There are three points to emphasise before proceeding, which should be borne in mind by the reader:

- First, the emphasis in our research and analysis was on identifying lessons from outside of the water sector and assessing their potential to be applied (with some adaptation) within the sector. Therefore, our primary focus was not on exploring good practice within the water sector itself. However, we do aim to identify good practice within the water sector in terms of understanding the extent to which good practice there is consistent with good practice in other essential services.

- Second, although we are confident that we have undertaken a very thorough review of theory and practice, it is important to acknowledge that some aspects of good practice are tacit. Good practice is not always captured or made available publicly, nor are senior stakeholders always aware of the full extent of it within their organisation. In this sense, there will always be aspects of good practice (and lessons) that we fail to capture. 
- Third, it is clear from published sources, the stakeholder interviews and the workshop with water sector representatives that practice in relation to affordability support varies considerably between different water companies. Whilst this will be the case across many other sectors, to varying degrees, it does mean that some water companies will already be operating in line with (or exceeding) good practice identified in other sectors, while others will have further to go. Therefore, we acknowledge that some of the good practice highlighted in this chapter will reflect current practice in parts of the water sector. In this sense, the challenge for the sector will be to achieve a consistently high standard of practice and innovation within and across all companies, particularly in relation to affordability support services offered, eligibility, targeting of those in need and definitions.

This chapter explores the following six key themes to emerge from our analysis of the literature, interview data and feedback from the workshop:

- Affordability support programme design and co-design.

- Shared platforms, data sharing and a streamlined customer journey.

- Partnership working and trusted intermediaries.

- Person centred approaches.

- Diversification of communication channels.

- The implications of Covid-19.

Each section reviews the key findings, assesses the extent of their applicability to the water sector and puts forward recommendations based on the evidence presented. The implications of Covid-19 for the good practice identified are discussed, where necessary, in relation to each theme and are also summarised at the end of the chapter.

\subsection{Key themes}

\subsubsection{Affordability support programme design and co-production}

\section{The homogeneity of programme and service designers}

There is a growing school of thought within the field of energy research that the success of initiatives designed to improve the circumstances of vulnerable and hard to reach groups, in terms of reaching a broad range of households and particularly those most in need, is influenced by the characteristics of those designing the interventions and associated communications (Ashby et al., 2020a, 2020b). More specifically, it is argued that a lack of diversity amongst programme designers, including those involved in the design of affordability support is resulting in initiatives that are designed from a narrow perspective and fail to take account of the needs, priorities and preferences for engagement amongst target groups. This proposition has emerged from an International Energy Agency (IEA) sponsored research collaboration spanning the UK, New Zealand, the USA and Sweden and is specifically focussed on energy users. However, the water sector is unlikely to be an exception to this issue, despite an increase (as noted in the stakeholder workshop) in the level of co-production activities undertaken by some water companies.

The issue of co-production is considered later in this section but the findings from the IEA project point to a more fundamental issue that may limit the potential for affordability assistance to reach those most in need from the point of conception, particularly households with the most complex circumstances. The remedy is, of course, to diversify those involved in shaping policies and initiatives so that their make up more closely reflects those being targeted and to create an environment oriented 
towards vulnerable consumers (the idea of a vulnerability focussed environment is covered later). Whilst this is an important longer-term aim (which was broadly supported at the stakeholder workshop as a valid challenge to the sector) which links closely with a series of broader agendas around workplace diversity, it cannot be resolved quickly. An important first step will involve water companies establishing a clearer, more detailed picture of their customer base and the variety of needs and preferences that exist within it as has been advocated for some time by CCW and against which some progress appears to have been made. However, there are other steps that can be taken more immediately to increase end user involvement in the design of affordability support, associated mechanisms for delivery and approaches to communication and promotion.

In this context, the Vulnerability Commitment established by Energy UK which we have already highlighted as good practice, is significant, having been created in response to feedback from customers in vulnerable circumstances regarding how things could work better for them. In this sense, the commitment represents a key mechanism for re-orienting affordability initiatives and associated practices firmly towards vulnerable customers, particularly because it is shaped by and relies upon their feedback. There are promising signs (that should be built upon) that vulnerability is becoming a more central theme within the water sector as denoted, for example, by the inclusion of affordability and vulnerability as a key strategic challenge in Ofwat's water innovation competition-a development which has the potential to be a key enabler of a sector wide vulnerability commitment.

\section{User involvement and co-production}

Through initiatives like the Vulnerability Commitment, we see the energy sector take a significant step towards creating a more direct line between vulnerable and harder to reach customers and programme design and service delivery, thus reducing reli ance on a homogenous set of programme designers. The water sector has similar ambitions and these are articulated in Ofwat's (2017) Customer Participation Report (Tapped In) which states that customer participation will become an additional principle of good customer engagement and that Customer Challenge Groups (which hold companies to account on their customer engagement) and Ofwat will expect companies to create and embed a customer led culture and to make this a board level commitment.

Empowering and harnessing user involvement is something that many Voluntary Community Sector (VCS) organisations have been doing for a long time and which underpin the sector's notable success and reputation for reaching hard to reach service users (Flanagan and Hancock, 2010). This success is explained with reference to the philosophy and operating models adopted in the VCS which include good treatment of service users including avoiding interrogation and asking only the questions necessary to help them; being welcoming and non-judgemental and being able to relate to clients and empower them (Flanagan and Hancock, 2010). The importance of this emotionally sensitive approach to service users will be explored further in Section 4.2.4 but it is important to note here that well developed processes for user involvement in service design are credited with creating this user focussed culture (Flanagan and Hancock, 2010).

These processes are now of ten referred to as co-production: an arrangement whereby citizens are involved, at least in part, in the production of the services they use (Bransden and Pestoff, 2006). In this context, one key commentator (Mazzei at al., 2019) cautions that the VCS is a vast and heterogeneous sector and that practice within it will vary considerably but that VCS organisations are often included in coproduction exercises either directly as a representatives of the views of service users or as a conduit to access harder to reach groups. 
Co-production can play a central role in improving the design, delivery, communication and targeting of affordability support and provides a key and immediate means of reducing the significance of problems associated with homogeneity amongst programme designers. However, it is almost impossible to establish the required mechanisms, engagement skills and strong relationships with a diversity of service users from scratch without support from relevant VCS organisations. Failing to engage relevant third sector organisations when attempting co-production exercises would be imprudent given their ostensible proximity to and deep understanding of vulnerable and hard to reach households, although many become overloaded because they are in high demand. Therefore, VCS organisations must be paid fairly for their contributions, enabling them to continue their work to support and represent marginalised groups.

Co-production does not necessarily involve establishing a direct line to vulnerable and hard to reach services users, as this involves a large amount of groundwork and the establishment of partnerships (as noted above). There are other ways in which the needs of service users can be better understood and accommodated whilst these foundations are laid.

If direct co-production or user-led design of services and programmes is at one end of the spectrum, at the other end lay a number of approaches that water companies could mobilise fairly quickly including co-production of service design with their own frontline workers, who, within the organisation, will be closest to service users (as advocated by Energy UK in their Vulnerability Commitment). The next step along might be involving relevant external organisations as external representatives of the views of target populations (as demonstrated by the Customer Challenge Groups that exist within the water sector to support business planning). Other steps may include appointing external research contractors to conduct regular, in-depth research into the experiences, needs and preferences of particular service users and to canvass their ideas about how services could be improved, as demonstrated by the work undertaken by Qa Research to inform Energy UK's Vulnerability Commitment. Such research may involve the establishment of a citizens panel of hard to reach service users who are returned to at set intervals (and paid for their time) to canvass their views on specific issues or proposals and to establish whether they feel the organisation is making adequate progress with regards to service and programme design. The concept of a citizens panel was demonstrated in joint research conducted by CRESR and Citzens Advice (see Ambrose et al., 2019) which used trusted intermediaries to identify and access hard to reach citizens. The important role of trusted intermediaries is covered in more detail in Section 4.2.3.

A further idea, which emerged from research into vulnerable people and smart meters (Hodges et al., 2018), identified how peer to peer conversations can be very effective in capturing service users' views in order to inform service design and commissioning arrangements. Peer to peer research can have significant benefits in terms of avoiding the negative consequences of a lack of trust, rapport and unequal power relations between researcher and subject (or company representative and customer), helping participants feel more at ease, open and authentic in what they are sharing. The power of peer-to-peer relationships in the context of affordability support has also been demonstrated through the long running BESN programme operated by the Department for Business, Energy and Industrial Strategy (BEIS) where a cascading training model is used to train community members to support each other with switching energy suppliers. The scheme has ostensibly been effective in engaging vulnerable households in these money saving activities and the peer-to-peer approach is regarded as a key success factor (Ambrose et al., 2015). Peer or 'community researchers' can also be employed as part of research projects yielding benefits in terms of the recruitment of participants and the richness of the data and could be required by water companies and sector wide organisations when commissioning 
research and consultancy. However, there must always be clear, ethical policies and protocols in place around the use of peer researchers and all forms of peer-to-peer engagement, that include access to training, fair payment and acknowledgement in outputs.

Peer support schemes, which include peer coaching models, buddying schemes or befriending initiatives, are another way that debt advice and other guidance and support is provided in collaboration with partner organisations. Such approaches and partnerships are common in the advice sector and in other sectors such as health working with third sector delivery partners. These methods are seen as an effective way of improving the engagement of people who are experiencing debt problems or other issues and of reaching vulnerable people. Coaches and mentors of ten have a shared previous personal experience with the people they are working with. Coaches and clients ideally meet via the channel (or combination of channels) of their choice, with some face-to-face contact which helps to encourage rapport. Coaches meet regularly with clients for a period of time, the aim being to put appropriate support in place which encourages the client to work towards a number of set goals or milestones.

Whilst it is more closely allied to consultation than co-production, Sheffield Hallam University's Listening Rooms provide another potential route to closer engagement with service users. As part of its mission to become a 'listening organisation', SHU has launched listening rooms as a way of capturing the views of staff and students in an authentic way. Anyone who works for or studies at the University can call into the listening rooms, essentially an answering machine, and anonymously share their thoughts and experiences. This creates a no-pressure approach where participants can be frank and open. This mechanism is much better suited to receiving feedback than offering supportdue to the need for anonymity, but can help considerably with service design.

There are a number of examples from across the water sector of water companies undertaking co-production activities in relation to aspects of service design. Those that have used co-production reported positive experiences, such as South Staffordshire and Cambridge water, which reported that co-production, with support from third parties, has led to service users heavily shaping policy development and design, minimising the role of company managers in the process. However, they emphasised the budget constraints limiting their co-production activities. Others reflected that their activities in this regard don't really amount to co-production and are instead presenting a largely finalised product to service users or those representing them and seeking their endorsement at a stage when there's limited scope to influence detailed design. It was also common for water companies to engage in co-production activities in relation to particular aspects of affordability support such as co-designing written material or webpages but not to extend this to the more fundamental aspects of programme design (i.e. what do customers need, how does the support offer respond to this and how are initiatives delivered and communicated).

Bristol Water also reported that co-production work with specific groups had 'made us see things in a different way'. The company had undertaken co-production workshops with older people in response to the fact that they few pensioners were coming forward for support. This completely changed the way that they promoted affordability support for people on Pension Credit and all communications approaches are now informed by co-production. This work was undertaken in partnership with relevant VCS organisations. In a further example, Northumbrian Water routinely set up customer workshops and customer experience surveys when making significant changes to their services and aim to engage customers in business planning and their support offer. 
In the field of debt advice, MaPs worked with debt advisers and customers to coproduce the future of remote debt advice services. Customers and advisers were actively involved in all aspects of the research and recommendations were based on the voices of over-indebted people and existing debt advice customers. It is hoped that such customer centred recommendations will enable change in the sector and support advisers to better meet customer needs (MaPS, 2020).

In a further example from the energy sector, aground-breaking research project called Being Warm Being Happy (Bradley et al., 2019), which focussed on adults with learning disabilities in fuel poverty, highlighted the importance of co-production of advice services, systems and written communications, for groups facing multiple barriers to engagement with key service providers. Moreover, the idea that specific groups that face multiple and complex barriers to engagement with support initiatives should receive targeted attention is something highlighted by the IEA collaboration on hard-to-reach energy users (Ashby et al., 2020a, 2020b). Being Warm Being Happy advocated the multiple benefits of co-production in this context and highlighted secondary benefits including the empowerment and upskilling of the target group in addition to the primary benefits of services, initiatives and communication tools that respond better to their needs. The project also underlined the importance of working closely with specialist advocacy organisations to engage populations with complex needs.

However it's approached, it's clear that routine thinking needs to be embedded across the sector around how the experiences, views, needs and preferences of end users, particularly those facing the most significant barriers, could be better represented in all aspects of service design, delivery and evaluation. Yet, for a sector fairly new to coproduction with customers, it makes sense to start small by working with one or two particular priority groups who are not engaging with affordability support, forging the necessary partnerships with key advocacy organisations and working with specialists in co-production to see what can be achieved. External evaluation of these projects and the outcomes associated with them over time will help to demonstrate the value of co-production approaches and generate learning to refine the approach which can be shared across the sector and with other essential services.

\section{Creating a vulnerability focussed environment}

Integrating co-production approaches routinely into the development and detailed design of affordability support is a key aspect of creating a vulnerability focussed organisation or perhaps a 'listening organisation', which places the needs of the most vulnerable customers at the centre of its mission and activities. The notion of a vulnerability focussed environment or organisation is a key part of the ethos underpinning Energy UK's Vulnerability Commitment which includes appointing a board level vulnerability champion to ensure that a commitment to vulnerable households is embedded at the most senior level of an organisation. The code will also be regularly reviewed by sector regulators, government and organisations representing vulnerable groups. There will be an annual request for information, and companies that sign up to the commitment will have to present to a panel of experts on how they are meeting the commitments. Other measures include: training of frontline staff to better identify and support vulnerable customers; Freephone numbers; seeking regular feedback on the accessibility of communications and commissioning regular research to understand how well vulnerable customers are being supported, ensuring that the commitment stretches from the board to the frontline. Co-production is not explicitly advocated but incorporation of a commitment to co-production could be something distinctive that the water sector could commit to.

The ethos of the Vulnerability Commitment seems to be filtering down to company level with Scottish and Southern Energy announcing their intention to be the most 
accessible and inclusive Distribution Network Operator in Great Britain. To help achieve this they have assembled a panel of independently chaired experts who work alongside their internal inclusive service panel to challenge thinking and provide innovative suggestions and practical ideas to further improve inclusivity.

Another area where a vulnerability commitment within the water sector might improve on what is already being done in the energy sector is to move beyond the training of call handlers and extend it to all frontline staff including engineering and maintenance staff and sub-contractors etc., ensuring that all representatives of the sector are sensitive to vulnerability and also have a working knowledge of the support offer available. This approach reflects the principles of MECC which was advocated as an approach for the sector in our last report to the CCW in 2016 (Ambrose et al., 2016). The MECC philosophy contends that every interaction (however informal) represents an opportunity to better understand customers and to raise their awareness of the support on offer. Where these interactions are performed poorly or inconsistently, likelihood or further engagement diminishes (CCVC, 2019).

Another way to enshrine a commitment to better meeting the needs of vulnerable customers is to sign up to the BS 18477 standard (Inclusive service provision) which specifies the procedures necessary to ensure that services are fair, ethical, inclusive and accessible to all customers. Both National Energy Action and Citizens Advice have advocated adoption of the standard across the energy sector as means of galvanising efforts to better engage hard to reach customers and offer higher quality support to vulnerable households. Some water companies have already signed up to the standard and it would be useful to understand how it has impacted on their organisation, their support of fer and the experiences of vulnerable customers. A sector wide commitment to the standard would be an obvious next step, perhaps as a key tool within a broader vulnerability commitment.

\section{Recommendations}

The discussion within this section on the makeup of affordability programme designers, co-production and the ways in which it can support the creation of a vulnerability focussed environment give rise to a series of short and longer term recommendations for the water sector, as follows:

- Wherever possible take opportunities to diversify the characteristics of policy shapers and programme designers. We accept that this is a long term ambition influenced by a range of other factors including legal frameworks and societal factors that determine who is qualified and comes forward for these roles.

- Work in the immediate term, to meet Ofwat's vision for greater customer participation by working towards a sector wide vulnerability commitment that goes beyond that adopted by Energy UK to encompass a commitment to co-production to improve all aspects of affordability supportdesign and provision and to a MECC approach where all frontline workers are vulnerability focussed.

- As part of this, enshrine a commitment to better meeting the needs of vulnerable customers by encouraging more water companies to sign up to meeting the BS 18477 standard (Inclusive service provision) as part of a sector wide commitment to the standard.

- In the immediate term, increase the level of co-production activity across the sector, evaluate and share good practice and lessons. Start with a focus on specific groups that are not engaging (in the style of Bristol Water's work with older people and Being Warm Being Happy's focus on adults with learning disabilities). This will involve laying the foundations for deeper engagement with vulnerable service users themselves (at a meaningful point in the process) by forging links with VCS organisations relevant to target groups and co-production 
specialists. In the interim, co-production with frontline workers, groups representing the views of vulnerable service users and regular in-depth research with target groups will help improve service design.

\subsubsection{Shared platforms, data sharing and a streamlined customer journey}

\section{Shared platforms}

A key theme in recent literature emerging primarily from the advice and energy sectors relates to the urgent need to streamline and improve the support journeys experienced by customers and particularly those in vulnerable circumstances. Currently someone who experiences a change in circumstances (such as job loss or income reduction) will have to approach each essential service provider (i.e. energy, water, telecommunications, financial services etc.) individually, suffering the distress associated with recounting their story repeatedly, completing numerous eligibility assessments and waiting for an offer of support from each provider. An added complication is that definitions of vulnerability and eligibility for affordability and other forms of support vary between and within essential services. So, while some service providers will deem the customer vulnerable and offer them support, others will not. In reality, if someone is deemed vulnerable by one essential service, they are likely to need support across them all (Citizens Advice, 2020). Moreover, this laborious approach to seeking support is likely to result in tense, clipped conversations that result in a poor understanding of the customer's circumstances and lead to misunderstandings and unrealistic expectations of the customer (Ambrose et al., 2019; Citizens Advice, 2020).

Citizens Advice (Cooper, 2020), amongst a number of other organisations, have backed the recommendations of the Commission for Customers in Vulnerable Circumstances (CCVC) and called for the simplification of this journey through asingle, secure online shared portal spanning essential service providers (the digital equivalent of a 'one stop shop') which offers a single assessment of eligibility (a passportable financial assessment based on the Standard Financial Statement) (CCVC, 2019) and unlocks a package of support spanning the providers involved. Such a portal, it is envisaged, could also allow customers to easily update their details, circumstances and data sharing preferences.

Ideas varied between sources as to which services might be involved, how such platforms would operate (i.e. would they be aimed at service users and/or third parties supporting them) and what geographical level they would operate on. The arguments for such an approach are hard to disagree with but there is, at the same time, widespread acknowledgement of the substantial challenges involved in making this happen, including issues relating to the sharing of personal data between organisations and working around issues of digital exclusion and lack of trust in providers and online platforms. However, the work of the government's Smart Data Working Group, which brings together essential services regulato rs and government departments to modernise data sharing and improve service delivery, is seen as akey starting point for unlocking the possibilities for shared platforms of this nature.

It is also apparent that efforts to develop and test such platforms across essential services at a more localised level are ongoing and have involved or even been spearheaded by water companies, as illustrated by the following examples:

- The Water Care app (South West Water) is an example of a water company offering a portal to unlock access to their full range of affordability support on the spot. The app has been developed for professional use during home visits and community events, allowing SWW and organisations working on their behalf (i.e., debt advice providers) to quickly sign customers up for the PSR, social tariffs and 
other linked support such as payment matching, direct payments from benefits, debt repayment grants, income maximisation etc.

- The North West Hardship hub, in which United Utilities participates, brings together information on the affordability support offered by a wide range of suppliers for those supporting people in debt. The service spans energy, water, telecommunications, housing associations, local authorities and local charities. Through the website, money advisors can search for available help locally and also rate and recommend schemes. The main value of this approach, is to help advice organisations navigate the affordability support landscape more effectively.

Both of these examples focus primarily on bringing disparate information together in one place and in the case of the Water Care app, enabling applications for support to be made during outreach activities. Nationally, CCW coordinate information on key affordability initiatives and associated eligibility criteria available across all water companies via their website to support professional advice providers. Whilst these resources undoubtedly provide useful tools for professional advisors trying to navigate the complex landscape of affordability support, they remain a long way from the kind of streamlined customer service journey advocated by the CCVC (2019) and others. Certainly, a resource or portal that can be operated by the customer themselves, if they wish and are able to, appears a distant prospect with the onus still firmly on professional advice providers to support vulnerable households through this complex landscape, as one interviewee emphasised:

"We rely on third party debt advice providers and we tend to push customers towards them and hope that the conversation will happen. The tools that have been developed have focussed on helping them to do their jobs more easily rather than improving our own ability." (Senior watercompany representative, interview).

\section{Data sharing and matching}

There are also calls for the work of the Energy Data Taskforce (which aims to transform energy related data infrastructure) to be extended to other key sectors. There is also a sense that the increase in sharing of Priority Services Register (PSR) data between the energy network and water companies is a step in the right direction to be built u pon (CCVC, 2019), especially since energy companies have become much more adept at signing eligible households up to PSR in recent years, enabling water companies to benefit from this.

However, this practice faces obstacles (particularly around the need for an aligned set of needs codes so information can be recorded consistently) and does not yet extend to the sharing of data related to eligibility for affordability support, although a pilot involving United Utilities identified the potential to assess customers (identified through data sharing with the energy network) for social tariff eligibility when signing them up to their PSR. Yet, eligibility for PSRs and financial vulnerability are not synonymous and using the PSR as a key route into conversations about affordability support risks narrowing the field and missing eligible customers.

Despite progress in relation to the sharing of PSR data and the logical argument that those qualifying for energy affordability measures should also qualify for water affordability support, water and energy companies face significant obstacles to further data sharing around eligibility for affordability support. This is primarily to do with the fact that water companies have clear geographical boundaries, whereas multiple energy companies will be represented in the same area and the mix of them will change all the time as people switch. PSR data can be transferred via the energy network operators, but the exchange of other data would require sharing agreements to be put in place with each energy company that a water company wanted to work with. 
In this vein, a promising recent development has been the engagement of a number of water companies in a DWP working group looking at automatically putting customers on social tariffs if they are eligible for certain benefits (such as the Warm Homes Discount or pension credits). This work flows from data sharing powers which were included in the Digital Economy Act (UK Parliament, 2017). The project is piloting the use of those powers to access basic data on whether a household is or is not in receipt of an income related benefit.

Energy sector representatives also point to the benefits of data matching processes to enable automatic qualification for the Warm Homes Discount (a one-off payment of $£ 140$ a year to eligible households). Through the stakeholder interviews, Energy UK and Ofgem representatives remarked on how automatic payment of the WHD has resulted in huge efficiencies for energy companies and reduces the need for customer engagement. An interviewee from National Energy Action made a related point, emphasising how costly is can be for companies to reassess eligibility annually or more frequently. In her view, this was wasted resource and unnecessary stress for the customer because, amongst the most vulnerable, eligibility is unlikely to change.

Whilst automatic payments may feel like progress, there are two main concerns related to this approach. First, a number of commentators caution against the use of welfare benefits as an eligibility criteria for affordability support in a utilities context, arguing that income is a better indicator of need and that simple proxies like this could miss up to $60 \%$ of those eligible (Gillard et al., 2017). However, it is acknowledged, in this context, that the introduction of Universal Credit has reduced the complexity and fragmentation of the welfare benefits landscape making it a more reliable way to identify those in need to affordability support. Yet, relying on this to determine eligibility still risks missing those with fluctuating incomes which cause them to regularly fall out of the system and have to re-apply; those who don't claim what they're entitled to; those waiting for claims to be processed and those on the margins of eligibility, sometimes referred to as the 'just about managing' (Hall et al, 2017). In relation to this, the stakeholder workshop revealed that some water companies seemed to have identified these pitfalls and were moving away from the use of benefits as a criterion and towards a broader focus on income and that these ideas were starting to permeate talks with DWP. Second, whilst automatic qualification for support reduces effort for both customers and professional advice providers supporting them, it removes the need for conversations with vulnerable customers that yield vital information about their needs and circumstances, which can help build trust and rapport and ensure they can access the breadth of affordability support on offer (i.e., income maximisation and debt advice) (Ambrose et al., 2016). As one interviewee put it 'Somebody who is in dire financial circumstances still needs an arm round their shoulder and somebody to sort it' (Senior water company representative). In light of this, it is perhaps more beneficial to use potential eligibility, as indicated by receipt of certain welfare benef its, as a 'foot in the door' or an opportunity to start a conversation with eligible households.

However, the point remains that possibilities for working with government on data matching opportunities opened by the Digital Economy Act (UK Parliament, 2017) could be of great value to the those offering affordability support, including water companies, and help identify a greater proportion of eligible households (providing the criteria extend beyond welfare eligibility), reducing reliance on them to come forward to seek support.

"Government has an awful lot of data about people who are in need, particularly when we're talking about trying to identify people who are in fuel poverty, financial need, there's a whole wealth of data in the benefits system there, and the Digital Economy Act of 2017 gave government significant powers to use that, and outside of the Warm Home Discount they've not really done it, so that's one I would 
highlight. This is particularly helpful because people are not necessarily good at self-identifying." (Energy UK representative, interview)

This is something that the water sector appears to have been proactive in exploring and exploiting. Indeed, it appears that the water sector is very close to the point where existing DWP data can be used to identify those eligible for Water Sure (a government scheme which caps water bills for some vulnerable people). This appears to be a key breakthrough given that, according to a senior water company representative, proving eligibility for this scheme is a laborious process for customers.

\section{Variation in eligibility criteria and the affordability support offer}

The significant variation in eligibility criteria for affordability support that exists within and between participating sectors is a huge challenge to the notion of shared platforms. CCW have called for better alignment of qualifying criteria within the water sector (CCW, 2019) but this represents just one step (albeit a significant one) along the long road to multi-sector shared platforms and much greater alignments of affordability support would be required across sector s to supportshared financial assessments and a coherent support offer (Cook, 2020). The energy sector is perhaps better positioned in this regard, with $~ 15$ companies having signed up to the Vulnerability Commitment (a commitment to vulnerable customers that exceeds licence obligations) launched by Energy UK, a key aim of which is to iron out inconsistencies in eligibility within and between energy companies.

As the stakeholder workshop underlined, a specific challenge in this context is that in the water sector, social tariffs are funded by cross-subsidy and water companies offer different levels of social tariffs and are limited in terms of how many households they can support. This means that it would be very difficult to automatically unlock support with water affordability for someone strugg ling to afford their energy bills. Deep reforms to the funding model underpinning affordability support in the water sector may therefore be needed before a shared platform could become a reality (Cook, 2020). Of course, it is possible for such a portal to unlock a support offer that varies between providers. However, this does not obviate the need to ensure that vulnerable households are offered appropriate and adequate support within and across essential services.

There are, however, indications that the pandemic may have moved the sector closer to a more consistent approach to affordability support. A number of interviewees and workshop participants highlighted how the sector got together at the onset of the pandemic and expediently agreed a consistent minimum support offer which was published in March 2020 and was reportedly developed very proactively by water companies in a collaborative manner. Water companies have reportedly shared good practice freely during the pandemic.

\section{Recommendations}

- Lay the foundations for a more joined up approach and drive-up quality and consistency of affordability support across the sector (a medium term aim)

In light of the multiple complications highlighted, our recommendation regarding this theme is for the water sector to lay the foundations for the possibility of a more streamlined experience for vulnerable customers through a secure, shared portal by continuing to participate in various initiatives seeking to improve data sharing and matching. Water companies should also seek to lead or participate in more localised pilots (see examples below) and to capture (through formal evaluation with an emphasis on qualitative understandings of the customer journey and outcomes) and share that learning across the water sector and essential services more broadly. The 
progress made in relation to the sharing of PSR registrations between the energy network and water companies and the work with DWP on automatic qualification for some benefit claimants should be built upon and extended to encompass other indicators of financial and non-financial vulnerability beyond welfare. The pursuit of a better experience for vulnerable customers in need of support should also give impetus to efforts to improve consistency of eligibility criteria and the affordability assistance offer between water companies as well as contributing to efforts to devise a passportable financial assessment which can be shared between two or more essential service providers. A vulnerability commitment, similar to that introduced by Energy UK, would help to galvanise these efforts and would represent a key step towards a greater degree of consistency across the sector in terms of the quality and availability of financial and non-financial support, eligibility criteria and approaches to identifying those in need.

There is considerable incentive for the water sector to push ahead with eff orts to streamline the customer journey with regards to affordability support, given that water arrears are the second largest form of debt owed to government and utilities with $£ 2,200$ million owed in 2018 ( $23 \%$ of the sector's income) (NAO, 2018) with the current figure likely to be much higher as a result of the pandemic. The water sector is owed twice as much as the energy sector, topped only by council tax arrears. There will be many reasons for this, including the lack of priority attached to water debt by many customers but accessible and user-friendly means of accessing affordability support are surely a key tool in reducing this level of debt.

\subsubsection{Partnership working and trusted intermediaries}

\section{Working through third parties}

Trusted intermediaries (usually frontline workers from VCS or public services that can help connect their clients to sources of help and support, e.g. healthcare workers; community development workers; housing officers, advocates etc.) can play a valuable role in making sure support, including affordability assistance, reaches customers in vulnerable circumstances (Ambrose et al, 2019; Flanagan and Hancock, 2010). This is a key recommendation of the NICE guideline, NG6, the basis of MECC (now widely applied across the water sector) and a key theme across the energy, health and advice literature.

There appears to be recognition within the energy and water sectors that certain types of organisations, mostly within the VCS and public sectors, benefit from a higher degree of trust than utility companies might as companies and creditors. Such organisations and those that represent them on the frontline also have the advanced skills and experience to gain access to vulnerable households and build a rapportsomething that large water companies would struggle to emulate. As a result, many utilities companies have forged partnerships with such organisations to help them deliver financial and non-financial support, either on an outreach basis where the partner organisations help to identify eligible households and/or through referrals made by utility companies.

The perception that VCS and public sector providers, of ten referred to as third party providers by utility companies, are more trusted by vulnerable households was emphasised by a number of those we spoke to:

"You need to bear in mind that customers, especially those who are more vulnerable, might prefer to engage with a third party for trust reasons. For this reason, some water companies fund third parties to do their outreach. At the end of the day, we're a creditor and people don't want to talk to a creditor or think a creditor can help them." (Water company representative, stakeholder workshop) 
Similar views were expressed by CCW representatives, who highlighted trust as a key driver of the reliance on third parties amongst utility companies in the context of affordability support:

"Water companies are not always trusted by customers who think that if they are asking them to sign up to things there must be an ulterior motive so on issues like metering and social tariffs water companies need to use or make better use of trusted voices or use CCW as the consumer body or other trusted organisations." (CCW representative, interview)

On the theme of trust, the Tapped In report produced by Ofwat (2017), challenges the water sector to go further in terms of their engagement with customers and to earn their trust. Whilst working with third party providers is clearly an effective way to broaden access to affordability support and target it at those in greatest need, it also establishes a regime which puts distance between water companies and their vulnerable customers. In this context, perhaps there needs to be a shift towards partnerships with third parties as more of a learning opportunity to enable a greater level of direct engagement in future. Certainly, some water companies are treating their partnership working with third parties as learning opportunities. For example, Northumbrian Water's relationship with debt advice provider, StepChange has been used to upskill call handlers around what to listen for in terms of cues that the customer should be referred for further support. Water company staff have also done call listening with StepChange to improve their call handling.

Another approach might be to more closely integrate water companies and the third party providers on which they rely rather than relying on referral mechanisms where the customer is passed to the third party and input from the water company falls away. However, the benefits of working through third parties for both customers and water companies are hard to deny, particularly in terms of the holistic support they can often offer to customers and engagement skills developed over a long period of time. Whilst closer relationships with customers open opportunities for water companies, particularly around water demand management, it is hard to see how affordability support can be delivered effectively without this specialist support.

During an interview, a representative of Northumbrian Water provided examples of their work with third parties, outlining the various partnerships they had forged with national and local organisations that they feel are better positioned to support the delivery of affordability assistance than they are or can broaden their reach:

"We bring in third party experts and have a number of different third party relationships with national organisations like StepChange but also have some local ones like Gateshead Council who have a good financial inclusion service/team and Gateshead Citizens Advice. Provide some more long term money management support, advice on savings etc." (Representative of Northumbrian Water, Interview)

Mostly these partnerships have a general focus on the provision of debt advice with links into a wider range of financial and non-financial support but sometimes they are focussed on a particular issue, mechanism or group felt to be particularly in need. Examples include Northumbrian Water's partnership with a foodbank charity which involved offering a month's free water to those using a foodbank to hook them into affordability support mechanisms. The geographical focus of water companies was felt to be an advantage in terms of their ability to forge partnerships with trusted organisations locally, something that energy companies would be poorly positioned to do. 
Through the stakeholder interviews, we also talked to trusted third parties providing these kinds of services to utilities to gain insight into their perspectives. Foundations Independent Living Trust (FILT) (a Home Improvement Agency that works in the homes of vulnerable households) supports a number of energy companies with delivery of affordability assistance programmes. They felt that energy companies approach them because of their ability to locate vulnerable households, direct resources towards them and are more trusted than even a local authority might be:

"We know where the vulnerable people on the PSR are. We have boots on the ground and engaged with every LA in the country. We have a granular knowledge of clients through local agencies and that's why we are really confident when we distribute money because we know that money is going to people who need it most." (FILT representative, interview)

Recent research into approaches to delivering and targeting fuel poverty interventions in island communities in the north of Scotland echoed these sentiments, emphasising how organisations with a long-term local presence and a high profile locally were best placed to ensure support reached those in greatest need. A connection to or the endorsement of local authorities was also an advantage (Sherriff et al., 2020).

The case for partnering with public sector and VCS partners is compelling and is an established approach to delivering affordability support and promoting take up across the water sector and beyond. It is also widely accepted as good practice within the literature on engaging hard to reach groups, maximising the chances that support will reach those in greatest need (Ambrose et al., 2019; Flanagan and Hancock, 2010; George et al.,2015). Further benefits of this approach include giving customers access to a more holistic support service- the kinds of advice providers that water companies are partnering with will be well positioned to link customers to support that goes beyond addressing their water affordability problems. As previously outlined, someone struggling to afford one utility will struggle across the board and independent advice providers can look at financial commitments across essential and non-essential services to broker a plan (Cook, 2020). They're also better positioned to have frank conversations with customers about the factors underlying their affordabil ity problems, potentially linking them to non-financial support where available and developing more sustainable solutions for the customer.

However, a water company representative that took part in the stakeholder interviews highlighted a potential pitfall of this model of referring customers on to third parties for support by outlining the potential for customers to become disengaged from the support process between being referred for help by a water company and the conversation getting taken up by the third party:

"It's worth exploring the single customer problem more, i.e. how do we make sure that customers are helped across the board when they contact one utility rather than have to ring round them all (water, energy, telecoms etc.). We push debt advice as the answer to this but that is always reliant on [the customer] going to a third party or us pushing them into a third party and then hoping that those conversations take place." (Representative of Northumbrian Water, Interview)

This point highlights the need for more robust mechanisms around the handover from water company to third party provider and unfortunately there is little in the way of good practice to draw upon in relation to this. Potential ideas include follow up calls to check that contact has been made; a system whereby third-party providers confirm they have had contact with the referred customer or a more immediate handover, such as a call transfer which reduces the risk of breaking the momentum. Such mechanisms are important in the context that, as research has shown, it may stretch the limits of vulnerable customers' confidence to make contact with a creditor and of ten this only 
happens when they reach desperation (Ambrose et al., 2019). It is therefore important that momentum is maintained once they take this step.

CCW representatives also pointed out how third parties can support water companies with awareness raising activities around their affordability support offer, as low awareness of the range of support on offer is a key barrier to take up and to more customers requesting support. It was proposed that incentives for water companies to work with third parties in this way could be incorporated in sector price reviews. However, they also cautioned that these activities would have to be undertaken locally due to the variation in the affordability support offer between water companies. Moreover, the limited budgets that water companies have negotiated with their customers for the purposes of affordability support can act as a disincentive to publicise affordability support too keenly. These restrictions give greater impetus to the need to ensure that the support on offer reaches those in greatest need.

A further challenge is around the extent to which the selection of third-party partners determines the mix of customers accessing affordability support. This point was raised by a local authority representative participating in the stakeholder interviews and was based on her experience of using third parties to promote access to affordab le warmth schemes. She commented that certain organisations were very keen to partner with them on this because affordable warmth schemes were a good fit with their priorities but some of these organisations had a narrow remit around, for example, age or ethnicity. Consequently, they found that referrals from some segments of the population were much higher than for others because of the groups prioritised by partners. This militated against their aim to direct resources to those most in need and highlighted the need to carefully select referral partners and ensure they represent the breadth of target groups. Similarly, Sherriff et al (2020) emphasised the need for multipartner networks rather than reliance on one or two key partners when seeking referrals for affordability support.

\section{Cross sector partnership working}

It was clear from the stakeholder interviews that partnership working was not just playing a key role in supporting the promotion of and referrals to affordability support but was also playing a key role in enabling the sharing of good practice across sectors. The establishment of a post within energy charity, NEA which focusses on water and energy poverty linkages and is funded, in part, by a water company, provides one prominent example and has enabled the exchange of good practice betwe en the water and energy sectors. A further example can be found in Northumbrian Water's aforementioned foodbank project which was inspired by N Power's energy vouchers scheme which was administered through foodbank provider, the Trussell Trust. Reportedly Citizens Advice played a role in flagging up the potential for a similar scheme within the water sector, underlining the importance of links to the advice sector which tends to have good knowledge of practice across essential services.

Moreover, a representative of Ofgem who participated in the stakeholder interviews emphasised how cross-sector working was increasing between the energy and water sectors, particularly at the regulatory level. He gave the example of knowledge exchange around protections for vulnerable customers but also pointed out how inherent differences between the sectors can be an obstacle to knowledge transfer. Nonetheless, closer working between the two sectors was welcomed and attributed, in part, to the commitment made by Ofgem in their Vulnerability Strategy to work more closely with other regulators recognising the linkages between different forms of poverty and the likelihood that someone struggling with energy affordability will also struggle to afford water. 
A CCW representative also praised closer working across the energy and water sectors and highlighted intentions to build knowledge of the water affordability offer amongst energy companies and vice versa to ensure that financially vulnerable customers are made aware of what is available in the other sector. They also emphasised the ambition to work more closely with government departments on affordability support i.e., raising awareness of water affordability support amongst benefit claimants.

Partnership working is also key in terms of holding utility providers to account in relation to their work with vulnerable customers. For example, the Vulnerability Commitment launched by Energy UK last year will be supported by an advisory board comprised of industry representatives specialising in vulnerability and debt, third sector representatives, BEIS and Ofgem who will meet twice a year to identify and evaluate the code to ensure it is as strong and relevant as it can be.

\section{Recommendations}

This section has demonstrated that partnership working on various levels is established practice within the water sector, that productive relationships have been built between the water and energy sectors in particular and that water companies make extensive use of the expertise of trusted intermediaries in promoting and delivering affordability support. However, a few recommendations are proposed in order to optimise these ongoing activities for the benefit of vulnerable customers, as follows:

- Wherever possible, water companies should regard partnerships with third parties as a learning opportunity to upskill staff in relation to successfully engaging with vulnerable groups and building a rapport.

- The sector should explore ways of working more closely with third parties that reduce the distance between water companies and vulnerable customers without undermining the benefits to customers. The objective here is to build closer relationships between water companies and their customers whilst also ensuring customers get holistic support from a trusted source.

- Cross sector lessons strongly suggest that water companies should very carefully select the third parties that they work with to provide affordability support, prioritising those closest to target groups and which are long established. Working with a range of partners that represent the breadth of target groups will avoid skewing support towards particular types of customer.

- If the water sector is to pursue a vulnerability commitment similar to that adopted within the energy sector, then a multi-partner advisory board should be assembled to review progress and challenge the sector to go further.

\subsubsection{Person-centred approaches to affordability support}

\section{Automatic eligibility versus person centred approaches}

The need for person-centred approaches to the provision of affordability support is a theme, both implicitly and explicitly, within the health and fuel poverty literature as well as the broader energy and vulnerability literature. A person-centred approach is essentially concerned with tailoring services to the needs, priorities, and preferences of the individual. The service should respond to their expectations rather than the other way around. The concept has gained traction in the health sector where personcentred care is one of the 13 fundamental standards that the Care Quality Commission requires healthcare providers to meet. Delivering a person-centred service requires listening to customers views, getting to know them and treating them with respect. It requires service providers to strike a delicate balance between being responsive to the 
specific needs of customers whilst also looking beyond their conditions or disabilities. In this vein, a recent fuel poverty study by Sherriff et al. (2020) concluded that vulnerability should not be seen as synonymous with a lack of capability or confidence.

The concept of aperson-centred approach brings together most of the themes outlined in this report. For example, it requires the involvement of customers in service designin this sense co-production is a pre-requisite of a person-centred approach. There are also close links to the creation of a vulnerability focussed environment, listening organisations and MECC, in the sense that every contact with a customer is an opportunity to better understand and record their needs and preferences. Trusted intermediaries can also play a key role in supporting customers to shape the service they receive and having in place a wide range of communications mechanisms can make the service more accessible to customers and increase opportunities for them to be heard. It also links (in part) to the idea, put forward by the IEA collaboration on Hard-to-Reach energy users, that the most complex subsets of customers, require highly customised affordability programmes (Ashby et al., 2020a, 2020b).

Person-centred approaches are particularly relevant in the context of affordability support and promoting take up, as a personalised service is more likely to be used (The Health Foundation, 2016). A similar observation was also made by an interviewee running a local authority fuel poverty support scheme:

\begin{abstract}
"You don't get a full picture of somebody's life by ticking a few boxes, you need staff who are willing to have good conversations with people to find out what's going on with them. You need to make every natural engagement point count with vulnerable people, ensuring they have support on a wide range of issues. If you do then you'll avoid assumptions about their lives, and you won't have to work so hard to engage them in future- they will come back to you." (Local authority representative, interview)
\end{abstract}

Related to this, is a debate ongoing within the energy literature regarding the merits of universal/data led approaches to allocating affordability support versus a more tailored approach. In recent years, key aspects of energy affordability su pport have been made automatic (so no engagement with the qualifying customer is required) using data matching techniques which automatically determine households' eligibility for certain schemes. Examples include payment of the WHD to low-income pensioners and a broader group of low-income households and the Winter Fuel Payment and Cold Weather Payment which is automatically paid to State Pension claimants and certain other benefit claimants. We heard earlier in the report how this automatic approach has yielded huge efficiencies for energy companies and reduced the need for customer engagement. However, such an approach places distance between companies and their customers and does not sit comfortably with the principles of a person-centred approach and the MECC agenda. Although, if a company is confident that it has strong co-production and customer engagement mechanisms in place then there is perhaps a case for a more distanced and automatic approaches to the delivery of some aspects of affordability support.

The academic fuel poverty and social policy literature is very critical of these universalised approaches and argues that attempting to level the playing field by topping up the income of lower income groups is a sticking plaster and fails to address the underlying disadvantages faced by qualifying households and the flaws in the system that cause affordability problems in the first place (i.e. high prices, liberalising the utilities markets, economic exclusion etc.) (Gillard et al., 2017). A number of key commentators call for a more just approach to affordability support that is based on redistribution and not universality. In this context, a re-distributional approach to affordability support plays a 'Robin Hood' role redistributing resource from the well off to the less well-off and prioritising those in greatest need (Hills, 2016). There is great 
support for the notion that the basis of all just and fair affordability support should be re-distributional rather than universal.

Universal benefits and automatic qualification represent an attempt to simplify processes associated with affordability support, reducing costs and bureaucracy. Using simple proxies to identify those in need is common practice amongst organisations involved in the provision of affordability support and the receipt of certain welfare benefits is the usual proxy employed to identify those most in need. We have heard earlier in this report that some water companies are eschewing this approach and looking to make assessments based on income instead. This seems wise based on estimates, related to fuel poverty, that using benefits as a proxy may result in missing a significant proportion of the fuel poor (Gillard et al., 2017), (even following the introduction of Universal Credit and the ways in which it accommodates fluctuating income levels through tapering) and geographical approaches based on the Index of Multiple Deprivation are also regarded as highly problematic. Using income as an eligibility criterion is not perfect either as it does not, for example, take account of concepts of vulnerability put forward by Ofgem which remind us that vulnerability is highly complex and dynamic and that someone can have an adequate income but fail to manage it effectively due to various vulnerabilities. As Hirsch (2019) points out in her work on the poverty premium: "low-income consumers cannot simply be regarded as consumers who are similar to others except with less money to spend. "

The use of simple proxies can also fail to recognise the concept of affordability, in the sense that some people may have adequate income but exceptionally high outgoings for various reasons including high energy costs due to living in poor conditions or may not be claiming benefits they are entitled to or with fluctuating income levels due to insecure employment. Our stakeholder interviews suggest that these issues and dilemmas are now recognised in the energy sector and are starting to be recognised in parts of the water sector, as the following quotes illustrate:

"I can see issues with how 'consumer vulnerability' and 'fuel poverty' are sometimes conflated, while these are linked, they are also distinctly different problems and financial and non-financial vulnerabilities often require different approaches". (Representative of Energy UK, interview)

"Some national energy schemes (e.g. WHD) have the advantage that they automatically put people on them but they don't take account of people's affordability so they can be a bit blunt." (Representative of Northumbrian Water, interview)

In essence, looking for simplicity in your response to vulnerable consumers may well become a false economy. Moreover, although government hold a wealth of data about people who are financially vulnerable, enabling them and organ isations they share data with to undertake seemingly robust data matching processes to allocate support, an awful lot is missed through this approach, such as those who do not appear to be financially vulnerable but struggle with affordability; those moving in and out of financial vulnerability and those just above the threshold that are sometimes referred to as 'just about managing'. And, as previously outlined, a reliance on data driven approaches puts distance between service providers and customers, flying in the face of much good practice, including that emanating from the water sector, around the importance of greater levels of customer engagement. It appears that a balance needs to be struck between using the powers of The Digital Economy Act (UK Parliament, 2017) to help identify eligible customers who would not necessarily self-identify but not to use this to replace more person-centred approaches to assessing eligibility and need and identifying the most appropriate financial and non-financial support measures available. 
Better understanding individual customers and their needs through detailed conversations is very important but there are also more systematic, overarching ways to ensure services are responsive to customer needs (especially those of the most vulnerable) which can support a person-centred approach at a more strategic level. Commissioning quantitative and qualitative research to better understand the customer base through bespoke surveys and interviews and supplementing this with insights from external data (i.e. Census data), where necessary can support the development of helpful typologies of customers which can, in turn, be translated into personas that put a human face to these typologies, making them real and relatable.

Personas are being used increasingly across a number of fields including in health care to support a more person-centred approach, as advocated by the National Institute of Health Research. They are also being advocated in architecture as a means of moving away from the practice of basing building design around profiles based on the average user (Buttitta et al, 2019; Ben \& Steemers, 2020). Personas, often used in social marketing, can help policy makers, programme designers, communications professionals and frontline workers to understand customer motivations, challenges, concerns and behaviours and to help ensure that policies, programmes, interventions and everyday service delivery resonates with them and works for them.

Personas articulated through 'pen portraits' have been used in fuel poverty research to improve the responsiveness of interventions to vulnerable consumers and to increase take up of support (see for example, the KWILLT project https://www.fuelpovertyresearch.net/wp-content/uploads/2016/10/FPRN-Salford-

2016-Tod-Pen-Portraits.pdf). This project used segmentation models, in-depth interviews and focus groups to inform an evidence based approach to persona development. Personas provide a way of articulating different segments of the customer base and are often given names, images and back stories to make them relatable. Personas were also used in a joint project between SHU and Citizens Advice (see Ambrose et al., 2019) to articulate vulnerable customers' experiences of energy advice services

(see

https://www4.shu.ac.uk/research/cresr/sites/shu.ac.uk/files/reaching-hardest-reachenergy-advice-final.pdf). Storyboards were used to sketch out two scenarios for each persona: their current energy advice experience and outcomes and an aspirational scenario. The steps necessary to transition from the current to the aspirational scenario were then mapped out. In addition to these personas, this project identified a typology comprising of fourbroad groups for whom energy advice needs to be tailored, including: 'new to this'; 'big lifestyle change'; 'balancing act' and 'can't do this alone'. This typology provides a tool which can either stem from persona development, seeking to summarise the customer groups with the highest needs or it can offer an alternative to persona development where resources are more constrained.

Monitoring impacts and outcomes for customers associated with their participation in a particular support initiative also play a key role in persona development, allowing for the inclusion of outcomes and customer journeys which support understandings of which types of support are best suited to each persona (Dobbins et al., 2016).

Both the CCW and Energy UK agree that demonstrating how relevant innovations and services are informed by an effective understanding of the characteristics of their vulnerable customer base is crucial in enabling engagement and targeting services at those most likely to benefit (CCW,2019; Energy UK, 2020). And it's clear that, within the water sector, there has been some activity around customer profiling and attitudinal segmentation modelling to guide communications strategies and identify groups to prioritise for mail outs in order to reduce costs. Some persona development has 
happened in some water companies, but this appears to have been used primarily to inform communications approaches rather than taking advantage of the full potential of personas and using them to raise awareness of the diversity of the customer base at board level, to guide the development of policies, initiatives, delivery routes and mechanisms and communications.

\section{Face to face engagement}

In our 2016 report to the CCW (Ambrose et al., 2016), we placed emphasis on the importance of face-to-face approaches when seeking to increase engagement with vulnerable customers and promote take up of affordability support amongst them. There is still significant support for face-to-face engagement within the literature and amongst those we interviewed and spoke to through the stakeholder event, despite the pandemic and the challenges it has raised in this regard. Face-to-face engagement, or at least offering a variety of ways to engage in line with customer preferences, is a key part of a person-centred approach.

Many, if not most, water companies appeared to have been doing face-to-face engagement either directly or through third parties on an outreach basis or in relation to individual cases for some time. This engagement was taking place in customers' homes and through events in communities. Many water companies expressed frustration that they have had to halt or reduce face to face engagement during the pandemic and were concerned about who they were not hearing from as a result, as the following quote illustrates:

"We did stop going out to do visits during the first lockdown, so the hard-to-reach groups more reliant on face to face engagement were just missed and getting that field force out has been essential. We have reinstated field visits now-we can still knock-on doors and have a conversation at a distance. Traditional customers coming through Citizens Advice face to face routes are a real worry- we are not seeing those as they have nowhere to go and we're not seeing evidence that they are taking an alternative route or approach, some will find alternatives but there is a group that is missing out." (Representative of Northumbrian Water, interview)

Although this company and several others had been able to re-start face to face engagement, there was concern that the inability to sit in someone's home, build a rapport that lends itself to sharing personal information and gain a full appreciation of their circumstances may mean that urgent support needs are missed. For example, being in the home, for whatever reason, allows support organisations to pick up on cues that the individual is struggling financially, for example: the room may feel very cold or they may notice that there is no money on the energy meter.

"Lack of face-to-face support means things will be missed - when you sit in someone's house and see their living conditions you get a much better sense than over the phone and will pick up on things that they won't self-report. However, client numbers are so much higher now supportcan be delivered over the phone. There will be need and desire for face-to-face to restart [in the water sector] for particular groups." (NEA representative, interview)

Further insights from social housing providers working to support financially vulnerable tenants underline the importance of face-to-face engagement in the home for seeing past the symptoms of the problem to the root causes and for handholding customers through the process of accessing support. One respondent from a housing association financial support team stated that about $85 \%$ of tenants who come through their service need an average of three home visits to put the required support in place. She recognises that this is a significant commitment of resources but argues that the investment results in more sustainable outcomes and that offering home visits is part 
of a culture of social responsibility, but which also has tangible benefits for income protection on the part of the organisation. The organisation has concluded that signposting is inadequate as a means of supporting financially vulnerable tenants. Moreover, the approach is paying off in terms of reaching hard-to-reach tenants with service monitoring data indicating that they are reaching those in greatest need, far more so than when relying on signposting approaches. The key to this success, they argue, is down to a person-centred approach that includes being prepared to vary the level of handholding required in line with customers' needs and preferences and placing no limits on the amount of support they provide to those in greatest need.

\section{Emotions and social relations}

A growing school of thought emanating primarily from the energy literature, which is closely linked to the theme of a person-centred approach, is concerned with the significance of emotions and social relations in determining how individuals approach the resolution of affordability and other energy related problems (Longhurst and Hargreaves, 2019; Hargreaves and Middlemiss, 2020). The key points emerging from this field of inquiry are also relevant to the context of water affordability.

It is now well established that when trying to resolve energy related problems that we do not act rationally, we act relationally (Hargreaves and Middlemiss, 2020). In practice, this means that rather than act on the instructions set out in a letter from a supplier or seeking independent advice, we are much more likely to ask people within our own social network what we should do. This has a lot to do with trust and power relations. Moreover, in the work of Longhurst and Hargreaves (2019), it is contended that our emotional state determines our approach to consumption and our propensity to seek help if we are not able to afford as much energy or water as we need. Where an individual has access to caring social networks, they are more likely to find a way through their difficulties but where these are absent; their chances of improving their circumstances are diminished. Fear, embarrassment, and stigma can stand between a customer and the possibility of support, whether from 'official' sources or from family or social networks. Thus, emotions are seen to play both negative and positive roles in shaping support journeys.

Linking back to discussions about the importance of face-to-face engagement in the home, Longhurst and Hargreaves go on to state that trust is critical in determining whether customers reach out for help and support and that building relations of trust can demand multiple emotionally charged meetings as part of the process of getting a full picture and thus being able to provide tailored help and support. Support providers need to be prepared to put in the emotional work to build trust and recognise that they are effectively strangers asking customers to share often quite personal, potentially embarrassing details about themselves, but also that customers themselves may be wary of their motives.

Other sources (e.g. Royston et al., 2014) also emphasise how engagement strategies need to consider how trust is built and how to provide information without overwhelming vulnerable groups and thus undermining trust. The Energy UK Vulnerability Commitment supports this view, emphasising how all reasonable steps must be taken to support customers to feel comfortable in disclosing vulnerabilities. Moreover, the complexity of eligibility for support measures is a barrier to accessing assistance primarily because making referrals sometimes necessitates timeconsuming and intrusive information gathering, especially in the context of complex and multiple problems (Royston et al., 2014). This requires friendliness, listening skills and empathy (Reeves et al., 2016) and an appreciation for domestic practices that low-income families must deal with such as choices between utility use and other basic needs, such as eating, and acknowledging the socially marginalising effects of living in poverty (Gillard et al., 2017). 
The literature also emphasises how social relations also have a bearing on the recruitment of vulnerable individuals into affordability support schemes, arguing that referrals increase where participants are approached through established social networks promoted by word of mouth rather than individually targeted (Romanach et al., 2014; Sherriff et al., 2020).

\section{Recommendations}

Building on earlier discussions about co-production, working through trusted intermediaries and the creation of a vulnerability focussed environment, this section has addressed the rationale for a more person-centred approach to the design and delivery of affordability support. It has explored the role that independent research and the creation of personas and typologies can play in everything from board level awareness to improving the design of initiatives, communications, and the customer journey. It has also discussed the evidence around the power of social relations and emotions in shaping our consumption, our approach to seeking help and the importance of doing the emotional work to create an environment where customers feel comfortable sharing their stories. The following recommendations/good practice principles are put forward with the aim of fostering more person-centred approaches in the context of affordability support:

- Be responsive to but also see beyond conditions and disabilities. Make no assumptions about vulnerable customers until you have the full picture and do not assume a lack of confidence and capability.

- Person-centred approaches operate as part of an eco-system which is informed and enabled by a commitment to co-production and deeper customer engagement, MECC, working with and through trusted intermediaries and making it easy for customers to communicate with you.

- Be prepared to invest time and resources in developing highly customised interventions for the most complex subsets of the customer base.

- Be prepared to have a series of detailed conversations with vulnerable customers (preferably within the home) to get the full picture of their circumstances before determining solutions.

- Carefully balance the potential efficiencies associated with data led approaches to determining eligibility for support against the potential to miss many eligible households and against the potential benefits of a more person-centred approach.

- Avoid reliance on simple proxies for determining eligibility by selecting the most appropriate eligibility criteria or identifiers for each support measure. Exercise caution around using welfare benefits, income and IMD data in isolation of softer indicators and the knowledge of trusted intermediaries.

- Invest in independent research to better understand the customer base, particularly vulnerable customers, and use this to develop tools such as personas and typologies that can inform all aspects of service design and delivery across all levels of the organisation. As part of this, put in place systems to monitor outcomes and impacts for customers associated with their engagement with affordability support.

- Face to face engagement in the homes of vulnerable customers is resource intensive but worth it in terms of reaching the hardest to reach and securing more sustainable outcomes for them.

- Make use of social networks and word of mouth to promote affordability initiatives and broaden referral pathways. 


\subsubsection{Diversification of communication channels}

There is clear consensus across the literature and the stakeholder interviews that customers should be offered as many different ways to communicate with essential service providers as possible, in order to accommodate a diversity of capabilities and preferences that may change frequently (over time and as the support journey progresses). However, increasing enthusiasm for digital options (i.e., websites, web chat, apps, instant messaging) and the apparent efficiencies they offer for service providers and some service users, threaten to narrow the range of options available to customers. This trend appears to have been accelerated by the pandemic which has galvanised moves towards digital communication and service provision. These debates link closely to the previous discussion about person-centred approaches which require flexibility in relation to communication and service delivery and responsiveness to the needs and preferences of all service users.

Key best practice sources such as the report of the CCVC (2019) and Energy UK's Vulnerability Commitment (2020) make clear how multi-faceted approaches to communication must be embraced for an organisation to make good on commitments to successfully engaging its most vulnerable customers. In this vein, the CCVC warn organisations not to close off more traditional options and emphasise that diversifying should mean adding to the range of options rather than removing those considered to be outmoded. They remind us that phone is still the most common method of communication with essential services (at least pre-Covid) and as previously outlined, a wealth of sources argue that face to face options are critical to the effective engagement of vulnerable customers. The CCW agrees that offering a range of options is the key, both in relation to communication and to other forms of service engagement, like paying for water:

"It's really important that there are a range of different channels for people to use and also to embrace digital offer, some water companies have Apps for meter readings and customers can make payments through those but many customers need more traditional offerings." (Representative of CCW, interview)

In this context, the CCVC highlight very clear examples of bad practice relating to anecdotal evidence of energy suppliers offering only app and online options for engaging with affordability support. Moreover, this point links to key findings from recent research from the Joseph Rowntree Foundation (Hirsch, 2019) which reveals how 'active consumers' (i.e., those with the skills, confidence and time to engage proactively with services) are better positioned to access the best deals and to exert pressure on service providers to offer them everything they're entitled to. The move towards digital service provision may favour more active consumers and particularly disadvantages the following groups: older households, social grades $D$ and $E$, lower income households, those with disabilities, private renters, social renters, those with no internet access, pre-payment meter consumers and those in arrears.

In this sense, the digitalisation of essential services and the broader ways in which service design favours active consumers contributes significantly to the perpetuation of the poverty premium (where lower income groups pay higher prices than wealthier counterparts). Considering this, a purely digital approach to the delivery of information regarding affordability support seems entirely inappropriate.

Further emphasising this point, a representative of Citizens Advice reported at interview that traffic to online and phone services has not increased much during the pandemic, suggesting that the most vulnerable, who are heavily reliant on face-to-face drop in provision have been falling by the wayside. Concern was expressed, in this context, about those with limited literacy and for whom English is a second language. A housing association representative who leads a financial support service made 
similar observations and saw a phone and online based service as a significant disadvantage to the most vulnerable:

"Unfortunately, thosealready most disadvantaged and who really require our help are the ones that suffer from the limitations of a telephone service. If we did not return to face-to-face contact for these circumstances it would severely impact our most vulnerable tenants and detract from what the service is able to achieve in terms of the prevention of tenancy failure." (Representative of a housing association financial support team, interview)

In this context, the respondent cautioned against viewing a phone-based service as almost as effective as face-to-face engagement because it's an established way of communicating. She highlighted how, amongst other things, it is difficult to have a truly private conversation and to create an environment conducive to sharing sensitive information when using the phone.

These are concerning observations, which were also made by several water company representatives at the stakeholder workshop and underpinned their ambition to return to face-to-face engagement and outreach work as soon as they could (indeed, some were already doing so in a limited way).

However, this is not to say that there are not opportunities associated with the greater push for remote service provision resulting from the pandemic, and interviewees from across a number of sectors highlighted how this had enabled them to find ways to streamline service provision with benefits to customers, including those in vulnerable circumstances. Examples of this from fuel poverty support include a local authority reducing the number of eligibility checks necessary for an affordable warmth scheme and reserving the use of home visits for those in need of them rather than as the default approach. A blended approach of using phone and home visits to raise awareness of the programme and sign households up for support will allow them to reach many more households in future and reduce waiting times to access services. However, such an approach needs to be accompanied by a clear set of criteria for making decisions about who benefits from a home visit.

This example also highlighted how, where an organisation has a strong understanding of their customers base, they can make better informed decisions about who to prioritise for face-to-face engagement. This underlines the importance of keeping a record of customers' engagement preferences on the basis that a vulnerable household is likely to need to engage repeatedly with affordability support, so intelligence can be built up and used to tailor the service to their needs. This approach is very much in line with the philosophy of MECC but is less about imparting information and more about gleaning insights into needs and preferences at each engagement.

It is also possible, as highlighted by one interviewee from the housing sector, that the greater emphasis on digital provision gives greater impetus to important efforts to boost digital inclusion amongst vulnerable populations to improve their access to a range of opportunities. However, this kind of support should only be provided to those that want it and should not be a pre-requisite of access to affordability support. It was also noted that some forms of affordability support are better suited to being done over the phone whilst others require a deeper understanding of a tenant's situation and are less likely to be successful if completed over the phone (i.e., appeals and Personal Independence Payment applications). There may be parallels within the water support offer than could be explored and certainly it would be useful to undertake an assessment of which medium is most appropriate for each type of affordability support, if this hasn't already been done. Of course, there is also a distinction to be made between what is the best medium for raising awareness of affordability support and 
what is the best way of supporting people to apply- the two issues are very distinct, and the latter requires greater rapport and trust than the former, given the need to share personal and financial information.

New possibilities for communicating with customers are emerging all the time and being able to match innovations to segments of the customer base most likely to use and benefit from them will be key to maximising their potential as engage ment tools. For example, a recent study commissioned by Citizens Advice (Cain and Goldring, 2018) highlighted the potential of instant messaging (in this case Whats App) as a widely used social networking platform with potential to support debt advice. WhatApp was revealed to be an effective way of providing debt advice, particularly to young people. It was found to reduce dropout rates, complement a range of other channels, and works well for speakers of other languages. The report particularly highlights how it provides a way of quickly supplying documents to an advisor (usually in photo form) but works best where a relationship has already been established through other channels.

Within the water sector, there are multiple examples of water companies operating multifaceted communication strategies which range from social media campaigns based on relatable case studies to socially distanced door knocking. The pandemic has also catalysed innovation in many parts of the sector with water companies appearing to trial a broader range of promotional campaigns (examples given include: adverts at bus stops, letters, leaflets, emails) around affordability support and attempting to increase communication with customers through multiple channels carefully timed to coincide with key events such as furlough ending, the new year, post-Christmas credit card bill dates etc. Joint communication campaigns with third sector organisations were also reported but despite all the innovation, some water sector representatives expressed concern that key messages are still not reaching those in greatest need and that there is a significant difference between hearing about what is on offer and being able to take steps towards claiming it. This, it was widely believed, is where outreach programmes come in.

The point about the timing of communication is important and several sources, including CCW, emphasise the importance of telling customers what they need to know when they need to know and via a communication method that they like (CCW, 2019). A message imparted at the wrong time will easily be forgotten. Interviewees from the housing sector talked about making the most of times when customers want to engage, and an Energy UK representative talked about 'hooks' that can be used to get people interested in what is on offer. He gave the example of using boiler replacement as the way into conversations about energy efficiency measures instead of focussing on insulation, which tends to be perceived as offering more distant benefits. The right hook might help to reduce any sense of stigma or embarrassment that might prevent someone seeking affordability support. Hooks for affordability support might involve highlighting alternative uses for money saved. However, it is important to remember that such messaging might stray into sensitive areas given that, for many low-income households, money saved on one utility bill is likely to be directed to other essential expenses such as food or energy (Beatty et al., 2014).

\section{Recommendations}

Good practice principles of relevance to the water sector highlighted in this section include:

- Offering affordability support by phone and online only is a significant disadvantage to the most vulnerable.

- There is a clear view from a range of key sources (notably the CCVC, Energy UK and $\mathrm{CCW}$ ) that offering a wide range of communication channels is critical to 
reaching vulnerable customers and improves the chances of engagement with affordability support.

- There are indications that greater enthusiasm for remote eng agement during the pandemic has resulted in some of the most vulnerable households (particularly those dependent on face-to-face provision) disengaging or being even harder to reach. It is therefore suggested that digital engagement innovations are added to a menu of possible engagement channels rather than replacing more traditional options.

- It is important to ensure that service design does not favour 'active consumers' better positioned to access the best deals and to exert pressure on service providers to offer them everything they are entitled to.

- If home visits are to be more limited in future then there needs to be a clear set of criteria for deciding who receives home visits, prioritising those least likely to use the phone or online services.

- Being able to match communication innovations to the segments of the customer base most likely to use and benefit from them will be key to making decisions about whether they are adopted or not and maximising their effectiveness where they are.

- Care should be taken over the timing of communication regarding affordability support and appropriate 'hooks' identified to create interest and overcome any sense of stigma or embarrassment.

\subsubsection{The implications of Covid-19 for affordability support}

Considerations relating to the pandemic have been explored throughout this section where relevant. However, this section highlights some key insights from across the literature and to a greater extent, the interviews with key stakeholders and the workshop with water sector representatives, which have not been highlighted elsewhere.

\section{Widening demand for affordability support}

It was widely emphasised through the interviews and the workshop that, as with all forms of affordability support, the pandemic has brought about changes in the numbers and characteristics of those seeking water affordability assistance and has also increased the scale of help requested. Although we did not have access to hard data on the types of customers that are seeking support now that were not previously, anecdotal reports point to the emergence of a new transient group of customers needing help that have been difficult to accommodate due to the limitations on the availability of some forms of affordability support (most notably social tariffs). It appears, in general, that whilst water companies have opened up to new ways of engaging with customers during the pandemic, funding models and eligibility criteria have proven less adaptable to increased demand from more diverse demographics, particularly those moving in and out of financial vulnerability due to fluctuations in the economy and in relation to furlough schemes.

It feels like a pivotal time for affordability support across the water sector, particularly for water companies whose schemes are getting close to capacity, as companies consider how to address sustained increases in demand brought about by the pandemic and its long-term consequences. It is likely that companies will have to increase availability of key forms of affordability support to manage the number of customers falling into debt. This will involve work to consult with and convince the wider customer base to back an expansion of social tariffs and/or companies to delve further into their profits. 
Other sectors also reported having to reduce promotion of their affordability offer to avoid being heavily oversubscribed and to allow themselves the headroom to identify and prioritise those in greatest need. These issues were reported across fuel poverty and housing related support services in addition to the water and energy sectors. However, the picture within the water sector appears more mixed, with some companies reporting increased communications campaigns (albeit mostly digital) around their affordability offer and others attempting to stem demand.

\section{Strategic level responses}

Other impacts have been felt at the more strategic level, with Energy UK delaying the launch of their Vulnerability Commitment at a time when it was arguably needed most. It was felt that introducing a substantial change agenda within the sector at this time would put additional, undue pressure on energy companies at a difficult time (Energy UK representative, interview). However, it could equally be argued that the pandemic has created powerful catalysts for re-inventing affordability support and forging more vulnerability focussed organisations, as demand for support surges and extends to a wider range of groups. In the end, the Commitment was only delayed by around six months.

Further examples from the energy sector indicate a very pro-active and vulnerability focussed approach to identifying and supporting those most at risk as a result of the pandemic. An interview with a representative of Ofgem revealed that the organisation undertook extensive'risk mapping' exercises at the outset of the pandemic to establish which customers would be rendered most vulnerable at this time. A key group identified through this exercise was those on pre-payment meters who may selfdisconnect due to an inability to top up. On this basis, talks were held between suppliers, government, and Citizens Advice about how to protect this group leading to an agreement between government (BEIS) and the sector to keep pre-payment meter customers connected to an energy supply during the pandemic through various measures including banning disconnections; discretionary top up funds and posting out of pre-loaded top up cards. This approach of using robust analysis to identify those at greatest risk and use this data to broker cross sector partnerships to reduce risks for this group must surely be held up as good practice for other sectors to learn from.

Returning to the water sector, the rapid, collective response of the water sector to the onset of the pandemic has been hailed as good practice and shared with the energy sector, demonstrating an ability to unite as a sector to ensure consistent minimum standards for customers in difficulty. Companies got together in March 2020 to agree a set of actions which included, inter alia: stopping court action and enforcement visits; expanding social tariff access, offering payment holidays; adjustments to payment plans and new methods of payment. These moves bode well for futurework to promote consistency across the sector in relation to affordability support. 


\section{Conclusions}

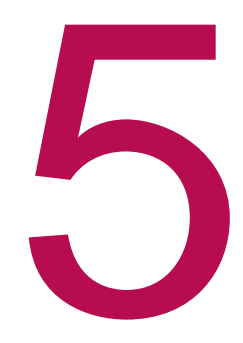

This final section of the report provides an opportunity to highlight some of the key points and good practice examples emerging from the research and to reflect on the strengths and limitations of the research undertaken.

This report has been informed by data from three key sources: the systematic review of $\sim 180$ publications spanning more than 10 sectors or service areas; in-depth interviews with 10 stakeholders representing six different sectors and detailed notes taken at a workshop with 15 water company representatives. This combination of activities allowed us to take account of published sources detailing practice and good practice whilst also garnering insights into unpublished knowledge of approaches to affordability support and the engagement of harder to reach customers held within relevant organisations. The workshop provided us with an opportunity to test the good practice identified through the review and the interviews in terms of transferability to the water sector. Moreover, the workshop afforded us greater insights into practice and innovation within the water sector, helping us to understand how the sector compares to good practice standards within other essential services.

We believe that this mix of research activities proved effective in generating a wealth of reliable and up to date material from which to distil a series of key good practice themes which in turn form the basis for a series of recommendations and good practice principles for the water sector. Given more time and resource, it may have been desirable to delve deeper into affordability support practice within the water sector through a greater degree of analysis of the vulnerability reports and strategies produced by each water company and through more interviews with stakeholders across the sector. This would have allowed us to more effectively benchmark good practice more accurately in the water sector against that demonstrated in other essential sectors to see where the sector leads and where it has further to go. However, the brief to review practice across a range of essential services reduced the emphasis on assessing the extent and nature of good practice within the water sector itself and has ensured that relevant practice within other sectors have been thoroughly explored.

\subsection{Overview of key points and recommendations}

The report begins with a review of current practice in relation to affordability support initiatives and delivery mechanisms across key sectors including energy, housing, health and advice. In this section we were only able to touch on a selection of the diversity of support measures and initiatives offered across these essential services. The key conclusion being that current practice is highly diverse both within and between sectors in terms of the support offered, eligibility criteria applied, channel provision, coverage, funding models and the nature of the customers targeted. This raises challenges for the exchange of good practice within and between sectors and 
services and presents a challenge to vulnerable customers trying to navigate this complex support landscape. In this vein, two key points emerged that were reinforced at several points in the report:

- $\quad$ First, that a greater level of consistency and coordination within the water sector between water companies and inter-sector between essential service providers more broadly is highly desirable in terms of better meeting the needs of vulnerable customers and supporting progress and innovation in relation to affordability support.

- Second, an individual requiring affordability support in relation to one essential service is highly likely to require support across them all, although they may have their own ideas about which service takes priority.

The identification of these two key points led to consideration of the emerging case for digital mechanisms to enable essential service providers to offer coordinated support to vulnerable customers and to streamline support journeys considerably. The discussion around this possibility is set out in section 4.2.2 Shared platforms, data sharing and a streamlined customer journey. This section concluded by recognising that there were many stubborn obstacles to the realisation of a cross-sector platform of this nature but that it remains a long-term aspiration. The interim recommendation for the water sector was therefore to help lay the foundations for this possibility by continuing to participate in various initiatives seeking to improve data sharing and matching; for water companies to continue to lead or participate in more localised pilots of such platforms and to capture and share the resultant learning. It was also argued that there is considerable incentive for the water sector to push ahead with efforts to streamline the customer journey, given that water arrears are the second largest form of debt owed to government and utilities (NAO, 2018).

This section also added to the case for improving consistency of eligibility criteria and the affordability assistance offer between water companies in preparation for closer integration. Energy UK's Vulnerability Commitment is held up as best practice throughout and a commitment of this nature within the water sector would represent a key step towards a greater degree of consistency across the sector in terms of the quality and availability of support, eligibility criteria and identifying those in need.

In section 4.2.1 Affordability support programme design and co-production, discussion turned to the makeup of affordability programme designers, co-production and the ways in which it can support the creation of a vulnerability focussed environment. Based on the material presented in this section, the water sector was urged (as a longterm goal) to take every opportunity to diversify the characteristics of policy developers and programme designers. In the more immediate term, we suggest working towards a sector wide vulnerability commitment that builds on the model put forward by Energy UK and encompasses a commitment to co-production and subscription to the BS 18477 standard (Inclusive service provision). In this vein, companies are similarly encouraged to increase the level of co-production activity with vulnerable customers, organisations representing them and frontline workers across the sector.

Greater emphasis on co-production necessitates forging closer links with VCS organisations relevant to target groups and co-production specialists- a key recommendation of section 4.2.3 Partnership working and trusted intermediaries. This section demonstrated that partnership working on various levels is established practice within the water sector, that productive relationships have been built between the water and energy sectors and that water companies make extensive use of the expertise of trusted intermediaries in promoting and delivering affordability support. However, a handful of recommendations were made to help water companies maximise the benefits of partnership working including finding ways of working more closely with third parties in order to reduce the distance between water companies and vulnerable 
customers without undermining the benefits to customers; working with a range of partners that represent the breadth of target groups to avoid skewing support towards particular types of customer and using a multi-partner advisory board to review progress and challenge the sector to go further as part of a sector wide vulnerability commitment.

Building on discussions about co-production and working through trusted intermediaries section 4.2.6 Person-centred approaches to affordability support addressed the rationale for a person-centred approach to affordability support. It explored the role that independent research and the creation of personas and typologies can play in everything from raising board level awareness to improving the design of initiatives, communications, and the customer journey. It also discussed the evidence around the power of social relations and emotions in shaping our consumption, our approach to seeking help and the importance of creating an environment where customers feel comfortable sharing their stories. The sector is reminded to:

- $\quad$ Be responsive to but also see beyond conditions and disabilities; make no assumptions about vulnerable customers.

- Develop highly customised interventions where necessary; approach simple proxies (i.e., using welf are benefit eligibility to determine eligibility for affordability support) and data led approaches to determining eligibility with caution.

- Invest in independent research into the customer base and experience as the basis for persona development.

- Monitor outcomes and impacts for customers in receipt of affordability support in the medium and longer term.

- Re-introduce face to face engagement when this proves possible as part of a commitment to making it as easy as possible for customers to be heard. An agreed set of criteria should be used to identify and prioritise those in need of home visits.

In relation to these latter points, section 4.2.7 Diversification of communication channels makes a clear case for offering customers a broad range of both digital and more traditional ways to communicate and engage with affordability support. The evidence presented highlights how the trend towards offering affordability support only by phone and online is a significant disadvantage to the most vulnerable. The sector is also reminded to ensure that service design does not favour 'active consumers' and develop clear criteria for deciding who receives home visits when they return; match communication innovations to the segments of the customer base most likely to use and benefit from them and keep a record of customers' engagement preferences.

\subsection{Timeframes and priorities}

The recommendations put forward in this report vary in terms of the timescales over which it is possible to put them into practice and variation in practice across the sector means that some companies will already be delivering them while other have further to go. The scale of action also varies in the sense that some recommendations can be taken forward at the level of the individual company whilst others require cross-sector commitment and thus may take longer to achieve.

A few recommendations stand out as immediate priorities:

- $\quad$ Beginning work, perhaps under the mentorship of Energy UK and the CCVC, to develop a voluntary vulnerability commitment for the water sector which builds on 
the energy sector commitment by incorporating an emphasis on co-production and references the BS18477 standard.

- Work closely with co-production specialists and specific VCS organisations to ramp up co-production, starting with specific groups that prove consistently hard to engage.

- Make more use of independent research providers to provide a deeper understanding of the customer base, help develop personas and typologies that can inform all aspects of service delivery and design. Linked to this, put in place robust monitoring procedures to track outcomes, and impacts for those in receipt of affordability support.

- Maintain traditional communication channels alongside digital options, carefully match communication channels to customer segments and ensure that the options provided do not favour active consumers.

\subsection{Key sectors and collaboration}

The table below sets out brief analysis undertaken to identify which sectors or service providers have formed the key influences on the recommendations set out in this report. This information is then used to suggest sectors and specific organisations where the water sector might most usefully focus efforts to forge new collaborations. Some suggestions relate to the development of close partnerships focussed on the exchange of good practice and knowledge (i.e., working closely with Energy UK/ the CCVC on a vulnerability commitment or Citizens Advice on shared platforms) and others to lighter touch 'following' of research and innovations to emerge from particular sectors (i.e., following research emerging from the IEA's HtR project; the Fuel Poverty Research Network or the Joseph Rowntree Foundation).

\begin{tabular}{|c|c|c|}
\hline Theme & Key influences & Suggested collaborations \\
\hline $\begin{array}{l}\text { Programme design } \\
\text { and co-production }\end{array}$ & $\begin{array}{l}\text { Energy sector (IEA, BESN, } \\
\text { Energy UK/ the CCVC); VCS } \\
\text { orgs; Advice (MaPS); Health; } \\
\text { specialist research providers. }\end{array}$ & $\begin{array}{l}\text { - Follow the work of the IEA annex on } \\
\text { HtR energy users. } \\
\text { - Energy UK/ the CCVC. } \\
\text { - MaPs. } \\
\text { - Research providers specialising in } \\
\text { co-production. }\end{array}$ \\
\hline Shared platforms & $\begin{array}{l}\text { - Advice sector (Citizens Advice) } \\
\text { - Energy UK/CCVC }\end{array}$ & $\begin{array}{l}\text { - Work closely with CA on this. } \\
\text { - Energy UK/CCVC. }\end{array}$ \\
\hline $\begin{array}{l}\text { Partnership working } \\
\text { and trusted } \\
\text { intermediaries }\end{array}$ & $\begin{array}{ll}\text { - } & \text { VCS } \\
\text { - } & \text { HIAs/FILT }\end{array}$ & $\begin{array}{l}\text { - Forming further alliances with VCS } \\
\text { orgs allied to the most HtR groups. } \\
\text { - Good practice exchange with FILT. }\end{array}$ \\
\hline $\begin{array}{l}\text { Person centred } \\
\text { approaches }\end{array}$ & $\begin{array}{l}\text { - Health } \\
\text { - Energy (fuel poverty) } \\
\text { - Research providers }\end{array}$ & $\begin{array}{l}\text { - Follow good practice emerging from } \\
\text { fuel poverty research through } \\
\text { membership of the Fuel Poverty } \\
\text { Research Network } \\
\text { - Specialist research providers to } \\
\text { support better understanding of the } \\
\text { custo mer base. }\end{array}$ \\
\hline $\begin{array}{l}\text { Diversification of } \\
\text { communications } \\
\text { channels }\end{array}$ & $\begin{array}{l}\text { - Advice } \\
\text { - Health } \\
\text { - Energy (Energy UK/CCVC) }\end{array}$ & $\begin{array}{l}\text { - Follow the work of CA on digital } \\
\text { innovations. } \\
\text { - Energy UK/ CCVC. } \\
\text { - Follow research coming out of JRF to } \\
\text { better understand the nature and } \\
\text { experiences of poverty. }\end{array}$ \\
\hline
\end{tabular}




\section{References}

Ambrose, A., Eadson, W., \& Pinder, J. (2015). Evaluation of the Big Energy Saving Network. London: $\quad$ DECC. Retrieved from http://www.shu.ac.uk/research/cresr/sites/shu.ac.uk/files/eval-big-energy-saving-network.pdf

Ambrose, A., Damm, C., Foden, M., Gilbertson, J. , \& Pinder, J. (2016). Delivering Affordability Assistance to water customers: cross sector lessons. Sheffield: CRESR, Sheffield Hallam University. Retrieved from http://www4.shu.ac.uk/research/cresr/sites/shu.ac.uk/files/delivering-affordability-assistancewater-customers.pdf

Ambrose, A., Baker, W., Batty., E., \& Hawkins., A. (2019). Reaching the 'Hardest to Reach' with energy advice: final report. Project Report. Sheffield Hallam University.

Ashby, K., Smith, J., Rotmann, S., Mundaca, L., \& Ambrose, A. (2020a). HTR Characterisation: Hard-to-Reach Energy Users Annex. UsersTCP, IEA.

Ashby, K., Smith, J., Rotmann, S., Mundaca, L., Reyes, J., Ambrose, A., Borrelli, S., \& Talwar, M. (2020b). Who are Hard-to-Reach energy users? Segments, barriers and approaches to engage them. In: 2020 ACEEE Summer Study on Energy Efficiency in Buildings: Efficiency: The Core of a Clean Energy Future (pp. 13-1). (ACEEE Summer Study on Energy Efficiency in Buildings). ACEEE. Retrieved from https://portal.research.lu.se/portal/en/publications/whoare-hardtoreach-energy-users-segments-barriers-and-approaches-to-engagethem(7c9a2021-333e-4936-b6c7-096dc4c41960).html

Beatty, T., Blow, L., \& Crossley, T. (2014) Is there a 'heat-or-eat' trade-off in the UK? Journal of the Royal Statistical Society. Series A (Statistics in Society), 177(1), 281-294.

Ben, H., Steemers, K. (2018) Household archetypes and behavioural patterns in UK domestic energy use. Energy Efficiency, 11, 761-771.

Bradley, J., Chapman, M., Damm, C., Farnsworth, V., Ferguson, A., Gilbertson, J., Owen, A., Stafford, B., Taylor, B., Tod, A., \& Wolstenholme, D. (2019). Being Warm - Being Happy (BWBH): Understanding Disability, Fuel Poverty and Energy Vulnerability for Adults with a Learning Disability. Kendal: Eaga Charitable Trust.

Brandsen, T., \& Pestoff, V. (2006) Co-production, the third sector and the delivery of public services. Public Management Review, 8(4), 493-501.

Buttitta, G., Turner, W.J.N., Neu, O., \& Finn, D.P. (2019) Development of occupancyintegrated archetypes: Use of data mining clustering techniques to embed occupant behaviour profiles in archetypes. Energy and Buildings, 198, 84-99.

Cain, E., \& Goldring, J.E. (2018). WhatsApp as a debt advice channel: Reaching people other advice channels do not reach. Manchester Metropolitan University.

Commission for Customers in Vulnerable Circumstances (CCVC) (2019). The Commission for Customers in Vulnerable Circumstances: Final Report. Energy UK.

Consumer Council for Water (2010). Cross-subsidies and Social Tarriffs: the consumer perspective. CCW: Birmingham.

Consumer Council for Water (2019). Water For All: Affordability and vulnerability in the water sector (2018-19). Birmingham: Consumer Council for Water. 
Citizen's Advice (2020). Getting support to those who need it: How to improve consumer support in essential services. Citizen's Advice.

Cook, J. (2020). Surviving the Wilderness: The Landscape of Personal Debt in the UK. National Energy Action.

Cooper, G. (2020). The coronavirus pandemic has shown we must get better support to people who need it - here's how. Retrieved from: https://wearecitizensadvice.org.uk/thecoronavirus-pandemic-has-shown-we-must-get-better-support-to-people-who-need-it-hereshow-4a6ee25d08d

Dobbins, A., Nerini, F., \& Pye, S. (2016). Measures to protect vulnerable consumers in the energy sector: an assessment of disconnection safeguards, social tariffs and financial transfers. INSIGHT_E.

Energy UK (2020). Vulnerability Commitment. Energy UK.

Flanagan, S.M., \& Hancock, B. (2010) 'Reaching the hard to reach' - lessons learned from the VCS (voluntary and community sector). A qualitative study. BMC Health Services Research 10(92).

George, M., Graham, C., Lennard, L., \& Scribbins, K. (2015). Tackling consumer vulnerability: regulators' powers, actions and strategies. Leicester: Centre for Consumers and Essential Services.

Gillard, R., Snell, C., \& Bevan, M. (2017). Advancing an energy justice perspective of fuel poverty: Household vulnerability and domestic retrofit policy in the United Kingdom. Energy Research \& Social Science, 29.

Hall, S.M., McIntosh, K., Neitzert, E., Pottinger, L., Sandhu, K., Stephenson, M.A., Reed, H., \& Taylor, L. (2017). Intersecting inequalities: The impact of austerity on black and ethnic minority women in the UK. Runnymede Trust and the Women's Budget Group.

Hargreaves, T., \& Middlemiss, L. (2020). The importance of social relations in shaping energy demand. Nature Energy, 5, 195-201.

Hills, J. (2016) The Distribution of Welfare. In P.Alcock, T.Haux, M.May, \& S.Wright (eds.), The Student's Companion to Social Policy (pp.212-217) Chichester, UK: Wiley-Blackwell.

Hirsch, D. (2019). Addressing the poverty premium: approaches to regulation. London: Consumer Futures.

Hodges, N., Goarman, D., Banks, N., Thumim, J., \& Lamley, A. (2018). Supporting vulnerable consumers to benefit from their smart meters. Centre for Sustainable Energy.

Longhurst, N., \& Hargreaves, T. (2019). Emotions and fuel poverty: The lived experience of social housing tenants in the United Kingdom. Energy Research \& Social Science, 56, 101207.

Mazzei, M., Teasdale, S., Calò, F., \& Roy, M.J. (2020) Co-production and the third sector: conceptualising differentapproaches to service user involvement. Public Management Review, 22(9), 1265-1283.

National Audit Office (2018). Tackling Problem Debt. Retrieved from https://www.nao.org.uk/wp-content/uploads/2018/09/Tackling-problem-debt-Report.pdf 
Ofgem (2019). Draft Customer Vulnerability Strategy to 2025. Retrieved from https://www.ofgem.gov.uk/publications-and-updates/draft-consumer-vulnerability-strategy$\underline{2025}$

Ofwat (2017). Tapped In: From passive customer to active participant. Retrieved from https://www.ofwat.gov.uk/wpcontent/uploads/2017/03/1941 OFWAT Cust Participation Report final.pdf

Reeves, A. (2016). Exploring Local and Community Capacity to Reduce Fuel Poverty: The Case of Home Energy Advice Visits in the UK. Energies, 9, 4.

Romanach, L., Hall, N., \& Cook, S. (2014). Behaviour change and energy consumption: a case study on engaging and retaining participation of low-income individuals. Community Development Journal, 49(4), 541-556.

Royston, S., Royston, S., \& Guertler, P. (2014). Reaching Fuel Poor Families: Informing new approaches the promoting take-up of fuel poverty assistance among families with children. Association for the Conservation of Energy and The Children's Society.

Sherriff, G., Lawler, C., Martin, P.B., Butler, D.E., Probin, M., \& Brown, P. (2020). Reshaping health services and fuel poverty in the Outer Hebrides. Project Report. University of Salford.

The Health Foundation (2016). Person-centred care made simple: What everyone should know about person centred care. London: The Health Foundation.

UK Parliament (2017). The Digital Economy Act 2017. Retrieved from https://bills.parliament.uk/bills/1859 


\section{Sheffield Hallam University}

Cross-sector review of affordability support: an evidence review for the Consumer Council for Water

AMBROSE, Aimee <http://orcid.org/0000-0002-5898-6314>, GILBERTSON, Janet <http://orcid.org/0000-0003-3338-7590>, SPEAKE, Beth, BIMPSON, Emma, MCCARTHY, Lindsey <http://orcid.org/0000-0002-5114-4288> and RAMSDEN, Sam

Available from the Sheffield Hallam University Research Archive (SHURA) at:

http://shura.shu.ac.uk/28699/

\section{Copyright and re-use policy}

Please visit http://shura.shu.ac.uk/28699/ and http://shura.shu.ac.uk/information.html for further details about copyright and re-use permissions. 